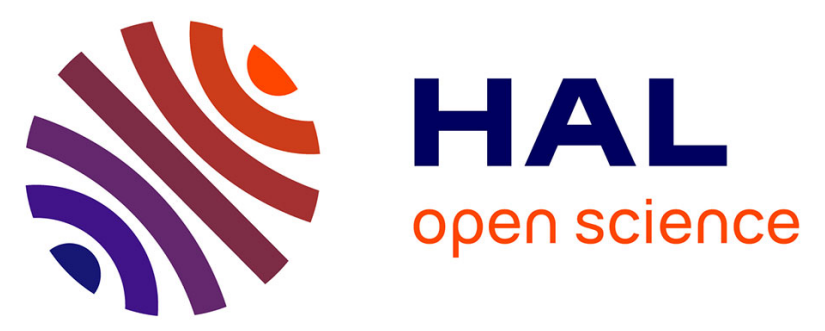

\title{
Tracking the role of nitrogen in the improvement of the high temperature oxidation resistance of titanium by mechanical treatments
}

\author{
L. Lavisse, P. Berger, A. Kanjer, V. Optasanu, Cyril Gorny, Patrice Peyre, \\ Manuel François, T. Montesin, M.C. Marco de Lucas
}

\section{To cite this version:}

L. Lavisse, P. Berger, A. Kanjer, V. Optasanu, Cyril Gorny, et al.. Tracking the role of nitrogen in the improvement of the high temperature oxidation resistance of titanium by mechanical treatments. Corrosion Science, 2022, 197, pp.110080. 10.1016/j.corsci.2021.110080 . cea-03525931

\section{HAL Id: cea-03525931 https://hal-cea.archives-ouvertes.fr/cea-03525931}

Submitted on 14 Jan 2022

HAL is a multi-disciplinary open access archive for the deposit and dissemination of scientific research documents, whether they are published or not. The documents may come from teaching and research institutions in France or abroad, or from public or private research centers.
L'archive ouverte pluridisciplinaire HAL, est destinée au dépôt et à la diffusion de documents scientifiques de niveau recherche, publiés ou non, émanant des établissements d'enseignement et de recherche français ou étrangers, des laboratoires publics ou privés. 


\title{
Tracking the role of nitrogen in the improvement of the high temperature oxidation resistance of titanium by mechanical treatments
}

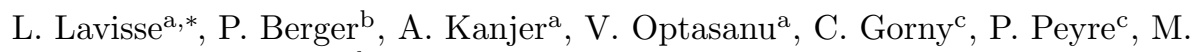 \\ François $^{\mathrm{d}}$, T. Montesin ${ }^{\mathrm{a}}$, M. C. Marco de Lucas ${ }^{\mathrm{a}, *}$ \\ ${ }^{a}$ Laboratoire Interdisciplinaire Carnot de Bourgogne, UMR 6303 CNRS-Université \\ Bourgogne-Franche Comté, 9 Avenue A. Savary, BP 47 870, F-21078 Dijon Cedex, France \\ ${ }^{b}$ Université Paris-Saclay, CEA, CNRS, NIMBE, 91191 Gif-sur-Yvette, France \\ ${ }^{c}$ Laboratoire PIMM, Ensam CNRS Cnam - Arts et Métiers - Sciences et Technologies - \\ Ensam 151 Bd de l'Hôpital, 75013 Paris, France \\ ${ }^{d}$ LASMIS, Université de Technologie de Troyes, 12 rue Marie Curie, 10010 Troyes Cedex, \\ France
}

\begin{abstract}
We report the role of ultrasonic shot-peening (SP) and laser-shock peening (LSP) on the insertion of atmospheric nitrogen during high temperature oxidation of pure titanium and the improvement of its oxidation resistance. Ion Beam analysis showed that for short oxidation durations, a layer of $\mathrm{Ti}_{2} \mathrm{~N}$ is formed at the oxide-metal interface. However, only the LSP treatment leads to the formation of a long-term stable nitrogen-rich layer which acts as a barrier for the diffusion of oxygen. This explains the efficiency of the LSP treatment to reduce the oxidation of $\mathrm{Ti}$ and prevent embrittlement.

Keywords: A. Titanium, B. Nuclear reaction analysis, C. High temperature corrosion, C. Mechanical surface treatments, C. Interfaces, C. Oxidation
\end{abstract}

\section{Introduction}

Titanium and titanium alloys are widely used in aerospace industry thanks to their light weight, high strength and excellent corrosion resistance up to $500{ }^{\circ} \mathrm{C}$

\footnotetext{
* Corresponding authors

Email addresses: luc.lavisse@u-bourgogne.fr (L. Lavisse), delucas@u-bourgogne.fr (M. C. Marco de Lucas)
} 
$[1,2]$ Titanium applications for aircrafts concern both airframes and engines. In airframes, titanium alloys have replaced steel to reduce weight. In turbo fan engines, titanium alloys are used for the fan and the compressor in the fore half section of these engines, where the temperature is relatively low $\left(600{ }^{\circ} \mathrm{C}\right.$ or lower). In the rear half section, where temperatures are higher, nickel-based alloys or iron-based alloys are used. However, their density is almost twice compared to titanium. Thus, a great reduction in weight could be obtained if the oxidation resistance of titanium can be improved.

At high temperatures, the growth of an oxide scale on the surface of titanium is accompanied by inward diffusion of oxygen which leads to the formation of a hard and brittle oxygen enriched layer beneath the scale, known as " $\alpha$-case" $[3,4]$. This reduces the mechanical properties of titanium, such as ductility, fracture toughness and fatigue life, and therefore is undesirable.

Mechanical surface treatments have widely been reported to improve the mechanical properties of Ti alloys [5-9], but several works have shown a beneficial effect on their high temperature (HT) oxidation behaviour. This effect was firstly observed in shot-peened pure zirconium by Surface Mechanical Attrition Technique (SMAT) [10]. Wen et al. $[11,12]$ studied the oxidation behaviour of SMAT treated grade 2 Titanium for short exposure to high temperature, $1 \mathrm{~h}$ at $500-700{ }^{\circ} \mathrm{C}$. The oxidation layer of SMAT treated Ti was thicker and denser compared to untreated Ti. This was explained by the numerous grain boundaries and dislocations induced by the SMAT treatment $[13,14]$.

Laser-shock peening (LSP) treatments on TC11 titanium alloy have shown a higher hot corrosion resistance in $\mathrm{NaCl}$ conditions [15]. For pure titanium, Kanjer et al. $[16,17]$ studied the influence of shot-peening and laser-shock peening treatments on the high temperature resistance in dry air. They showed a decrease of both the oxide scale thickness and the oxygen diffusion depth in LSP treated titanium plates.. Recently, He et al. [18] have reported the improvement in oxidation resistance of $\mathrm{Ti}_{2} \mathrm{AlNb}$ alloys at high temperatures by LSP treatment.

The high temperature oxidation behaviour of pure titanium was studied by 
Chaze and Coddet [19] between 500 and $700{ }^{\circ} \mathrm{C}$ in pure oxygen and in air, for oxidation times up to several thousand of hours. They reported that the oxidation rate of pure titanium in air is lower than in pure oxygen and concluded that the atmospheric nitrogen significantly modifies the oxidation process of titanium in air. Three hypotheses were proposed to explain these effects. The first one was that the diffusion of nitrogen through the rutile oxide scale is favored compared to that of oxygen. The situation is reversed at the oxide/metal interface and nitrogen diffusion diffuses more slowly than oxygen in the metal. The result is a progressive accumulation of nitrogen near the metal-oxide interface. The other hypotheses were: i) a decrease in the concentration of oxygen vacancy in the rutile scale, and ii) a decrease of the oxygen solubility within the metallic alloy. However, the insertion of nitrogen in oxidized pure titanium was not directly shown by any of the experimental techniques used by Chaze and Coddet [19] who based their conclusions on the microhardness profiles measured along the cross-section of oxidized samples to obtain the oxygen concentration profile. It is worth noting that the detection of low concentrations of nitrogen in titanium alloys cannot be addressed by Energy-Dispersive X-ray Spectroscopy (EDS) due to the proximity of the X-Ray emission lines of titanium and nitrogen.

Other authors have also reported a smaller oxidation rate of titanium in the presence of nitrogen [17, 20-23]. Kanjer et al. [17] showed, by Ion Beam Analysis (IBA) techniques, the presence of a nitrogen-rich layer at the interface in pure titanium oxidized at $700{ }^{\circ} \mathrm{C}$ for $100 \mathrm{~h}$ in dry air. Ion Beam Analyses (IBA) are powerful techniques to quantify light elements and to study their distribution [24]. For LSP treated titanium, a continuous nitrogen-rich layer was observed, while this layer was discontinuous in SP treated and untreated titanium. These results were in agreement with thermogravimetric analyses which showed a smaller oxidation of LSP treated pure titanium compared to SP treated and untreated titanium [17].

Berthaud et al. [25] studied the oxidation in air of Ti6242S at $560{ }^{\circ} \mathrm{C}$ up to $10000 \mathrm{~h}$. They showed by XPS and EDX-TEM analyses the presence of a nitrogen-rich layer located at the outer part of the alloy, and oxygen dissolution 
below. The role of nitrogen in the oxidation of Ti6242S at $650{ }^{\circ} \mathrm{C}$ was studied by Dupressoire et al. [23]. They reported thermogravimetric analyses up to $100 \mathrm{~h}$ in a mixture of $20 \% \mathrm{O}_{2}-80 \% \mathrm{Ar}$ and in synthetic air $\left(20 \% \mathrm{O}_{2}-80 \% \mathrm{~N}_{2}\right)$. In the latter case, they showed a slowing down of the growth of the oxide layer and a lower dissolution of oxygen in the alloy. Abdallah et al. [26] extended this study to longer oxidation times of $1000 \mathrm{~h}$ to investigate the oxide-alloy interface by STEM-EELS technique. They identified the formation of titanium nitrides (TiN and $\mathrm{Ti}_{2} \mathrm{~N}$ ) and oxynitrides which support the first hypotheses proposed by Chaze and Coddet [19]. Recently, Dupressoire [27] reported the study of this system by atom probe tomography. They confirmed the formation of a $\mathrm{Ti}_{2} \mathrm{~N}$ interfacial layer of titanium oxynitrides and nitride and showed the formation of a nitrogen rich alpha-titanium based solid solution which act as a barrier for oxygen. Xu et al. [28] have also reported the formation of an interfacial $\mathrm{Ti}_{2} \mathrm{~N}$ layer in the oxidation of the novel Ti-0.5Nb-0.5Si alloy at $650-850{ }^{\circ} \mathrm{C}$ in air. For near- $\alpha$ titanium alloy TKT 41, Kitashima et al. [29] reported the formation of a thin nitrogen-rich layer on top of the metal for short exposure to high temperature. The increase of the concentration of nitrogen by increasing the exposure duration was associated to a recrystallization process of grains at the interface including the formation of nitrides, $\mathrm{Ti}_{2} \mathrm{~N}$ and $\mathrm{Ti}_{3} \mathrm{AlN}$.

All the above works show that atmospheric nitrogen is actively involved in the high temperature oxidation of titanium, coupled or not with a mechanical treatment. In this work, we investigate the role of nitrogen in the high temperature oxidation of shot-peened (SP) and laser-shock peened (LSP) pure titanium compared to titanium that has not been subjected to these treatments (called here untreated titanium (US)). The goal was to investigate the effect of these mechanical treatments firstly on the insertion of nitrogen in the first stages of the oxidation process in dry air at $700{ }^{\circ} \mathrm{C}$, and then for long exposure times $(3000 \mathrm{~h})$ to high temperature.

Ion Beam Analyses (IBA) and nuclear microprobe methods were mainly used to analyse the distribution of oxygen and nitrogen in the oxidized samples. Structural characterizations by scanning electron microscopy (SEM), X- 
ray diffraction (XRD) and micro-Raman spectroscopy were also done. Crosssection micro-hardness profiles were also measured for long-time oxidized samples. The beneficial effect of LSP treatment on the high temperature oxidation resistance of pure titanium and the role of nitrogen in the oxidation process are discussed in the light of the different results reported here.

\section{Experimental details}

\subsection{Material and mechanical treatments}

The material used here was $1 \mathrm{~mm}$ thick Titanium plates (grade I, certified purity $99.6 \%$, Goodfellow). The plates were produced by cold-rolling and annealing. The plates were cut into $50 \times 25 \mathrm{~mm}^{2}$ rectangles for mechanical surface treatments (shot-peening and laser-shock peening). After the surface treatment, $10 \times 8 \mathrm{~mm}^{2}$ samples were cut for thermo-gravimetric analyses. The corners and edges were slightly rounded in order to avoid geometrical singularities that could lead to delamination of the oxidation layer during the cooling of the sample.

Two kinds of mechanical treatments were used in this work: ultrasonic shotpeening (SP) and laser-shock peening (LSP). Experimental details on both kind of treatments are given in previous papers [30] [16].

Basically, ultrasonic shot-peening (SP) was performed by surface mechanical attrition treatment (SMAT) using $20 \mathrm{~g}$ of $2 \mathrm{~mm}$ diameter tungsten carbide (WC) balls. The WC balls are put into motion in a closed chamber (15 $\mathrm{mm}$ in height) by a titanium sonotrode which vibrates with an amplitude of $12 \mu \mathrm{m}$. The frequency was fixed at $20 \mathrm{kHz}$. The duration of the treatment was $30 \mathrm{~min}$ by face with reversing of the treated face each 10 minutes in order to keep bending deformations reasonable.

LSP treatments were done using a GAIA HP laser source operating at a $532 \mathrm{~nm}$ wavelength which reduced laser beam absorption in the confinement media and increased the effect of the treatment. A focused beam with a typical $3 \mathrm{~mm}$ spot diameter was used. The laser shot frequency was $0.5 \mathrm{~Hz}$ and the pulse duration was 7 nanoseconds. The laser irradiance was $9.1 \mathrm{GW} / \mathrm{cm}^{2}$. In 
this range, each laser impact generates a plasma plume over the target which is confined near to the surface of the sample by the confinement media. Here, water was used as a confinement media to increase the shock amplitude and duration. When the plasma blows off, the shock-wave generated into the target induces plastic strain through twinning and a small amount of work hardening. The plastic strain incompatibilities give a gradient of residual stresses in the depth of the specimen. The laser scans the sample surface with a velocity of $1.1 \mathrm{~mm} / \mathrm{s}$. This leads to an overlapping area of $30 \%$ between two successive impacts. LSP treatments were performed on both faces of the sample. The laser path was snake-shaped by describing successive displacements along parallel lines going and coming. The samples were covered during the laser shock by an aluminium adhesive coating film to prevent their oxidation during the LSP treatment and avoid thermal effects.

For simplicity, shot-peened samples are named here SP, while laser-shock peened samples are named LSP in the following sections. Untreated samples (further named US) were also studied for comparison.

In the following, the duration of high temperature oxidation experiments will be added to the sample name. For example, SP-5h designates shot-peened samples oxidized for 5 hours.

\subsection{High temperature oxidation experiments}

The samples were oxidized in synthetic dry air at $700{ }^{\circ} \mathrm{C}$ in two different ways for various exposition times. For short oxidation times (5 and $10 \mathrm{~h}$ ), the variation of the mass gain was measured by thermogravimetric analysis (TGA) with a Setaram SETSYS Evolution 1750 thermal analyzer in isothermal conditions. For long oxidation times (3000 h), non-isothermal conditions were used. The samples were placed in a SETNAG furnace at $700{ }^{\circ} \mathrm{C}$ in dry synthetic air. They were regularly extracted from the furnace, cooled down and weighed before being replaced in the furnace. 


\subsection{Characterization techniques}

\subsubsection{Ion beam analysis}

The elemental analysis of the samples was done by ion beam analysis within the nuclear microprobe of the LEEL Laboratory (France)[31]. Rutherford backscattering (RBS) and Nuclear Reaction Analysis (NRA) experiments were done by using a beam of deuterons. A particle detector with annular shape and average detection angle of $170^{\circ}[32]$ was used for detecting the particles resulting from the interaction of the incident beam and the samples (Fig. S1 in Supplementary Information).

Different deuteron beam energies were used for optimizing the detection of oxygen and/or nitrogen and determining their concentrations. For non-oxidized samples or short oxidation times (5h), a deuteron beam of $1.45 \mathrm{MeV}$ perpendicular to the surface of the samples was chosen for the detection of the three light elements ( $\mathrm{O}, \mathrm{N}$ and $\mathrm{C})$ [33]. The depth of the analysed area was estimated at about $5 \mu \mathrm{m}$ by using PYROLE software [32], which is larger than the thickness of the oxide layer in $5 \mathrm{~h}$ oxidized samples. Therefore, the whole thickness of the oxide layer was analysed in this case. Table 1 summarizes the calculated energy of the different nuclear reactions of oxygen, carbon and nitrogen for an incident deuteron beam of $1.45 \mathrm{MeV}$. The reactions labeled $O 2, C 1$ and $N 3$ in Table 1 were mainly used for detecting oxygen, carbon and nitrogen, respectively.

For long oxidation times $(3000 \mathrm{~h})$, the thickness of the oxide scale is larger than $10 \mu \mathrm{m}$. Cross-section analyses were done in this case. In order to optimize the sensitivity of detection of oxygen or nitrogen, specific experimental parameters were used. For oxygen detection, the beam energy was fixed at $0.92 \mathrm{MeV}$ and a $23 \mu \mathrm{m}$-thick Mylar foil was placed in front of the detector to absorb the backscattered ions and let pass only the particles produced by the nuclear reactions. This is one of the best options to detect the ${ }^{16} O\left(d, p_{1}\right){ }^{17} O$ nuclear reaction (labeled $O 2$ in Table 1 [31, 32, 34]. For nitrogen detection, a beam energy of $1.9 \mathrm{MeV}$ and a $50 \mu \mathrm{m}$-thick Mylar screen were used to improve the detection of the ${ }^{14} N\left(d, \alpha_{1}\right){ }^{12} C$ nuclear reaction ( $N 3$ in Table 1) [35]. For 
mapping the cross-section of oxidized samples, the scanning step was $2 \mu \mathrm{m}$ and the size of the incident beam was $5 \times 3 \mu \mathrm{m}^{2}$. Therefore, the spatial resolution along the depth was higher than $2 \mu \mathrm{m}$.

\subsubsection{Microstructural characterization}

Phases analysis was done by XRD with grazing incidence $\left(2^{\circ}\right)$ X-ray diffraction with a BRUKER D8-A25-DISCOVER device using $\mathrm{Cu}-\mathrm{K}_{\alpha}$ radiation.

The cross-section of oxidized samples was resin-coated and mirror-polished. Observations by SEM were done using a Tescan Vega 3 microscope in backscattering electrons (BSE) mode. Beneath the oxidation layer, the orientation of the grains in the sample cross-section was studied by Electron Backscattered Diffraction (EBSD) using a TSL EDAX OIM X4 M EBSD system coupled with a field-emission scanning microscope (FE-SEM, JEOL JSM-7600F). The working distance was $20 \mathrm{~mm}$, the tension $20 \mathrm{keV}$, magnification x 70 and a step of $1 \mu \mathrm{m}$.

Raman spectra were obtained with an InVia Renishaw set-up working in backscattering configuration. The wavelength was $532 \mathrm{~nm}$ and the excitation power was relatively low (about $0.5 \mathrm{~mW}$ ) to avoid heating the samples. Both sample surfaces and cross-sections were studied in this way.

Micro-hardness measurements were done on the cross-section of oxidized samples in order to investigate the extension of the $\alpha$-case. A ZWICK/ROEL indenter (Vickers diamond pyramid) was used with a load of 50 gf applied for $10 \mathrm{~s}$.

\section{Results and discussion}

\subsection{Impact of SP and LSP treatments on the raw material}

\subsubsection{Microstructure of mechanically treated Ti plates}

The cross-section of US, SP and LSP samples was studied by SEM and EBSD before high temperature oxidation experiments. Figure 1 shows the images obtained for the three kinds of samples. The US sample shows equiaxed grains with a size of about $40 \mu \mathrm{m}$. After the SP treatment, SEM and EBSD images 


\begin{tabular}{|c|c|c|c|c|}
\hline & & $\begin{array}{l}\text { Deuteron beam: } \\
\mathrm{E}=0.92 \mathrm{MeV} \\
\text { Mylar foil: } 23 \mu \mathrm{m}\end{array}$ & $\begin{array}{c}\text { Deuteron beam: } \\
\mathrm{E}=1.45 \mathrm{MeV} \\
\text { No Mylar foil }\end{array}$ & $\begin{array}{l}\text { Deuteron beam: } \\
\mathrm{E}=1.90 \mathrm{MeV} \\
\text { Mylar foil: } 50 \mu \mathrm{m}\end{array}$ \\
\hline Label & Reaction & $\mathrm{E}(\mathrm{MeV})$ & $\mathrm{E}(\mathrm{MeV})$ & $\mathrm{E}(\mathrm{MeV})$ \\
\hline RBS O & RBS O & - & 0.88 & - \\
\hline RBS Ti & RBS Ti & - & 1.23 & - \\
\hline RBS W & RBS W & - & 1.39 & - \\
\hline O2 & ${ }^{16} O\left(d, p_{1}\right){ }^{17} O$ & 0.82 & 1.94 & 1.06 \\
\hline$N 10$ & ${ }^{14} N\left(d, p_{6}\right){ }^{15} N$ & - & 1.87 & - \\
\hline$N 9$ & ${ }^{14} N\left(d, p_{5}\right){ }^{15} N$ & 1.09 & 2.10 & 1.30 \\
\hline$N 8$ & ${ }^{14} N\left(d, p_{4}\right){ }^{15} N$ & 1.27 & 2.23 & 1.49 \\
\hline$O 1$ & ${ }^{16} O\left(d, p_{0}\right){ }^{17} O$ & 1.85 & 2.71 & 2.17 \\
\hline$N 7$ & ${ }^{14} N\left(d, p_{3}\right){ }^{15} N$ & 2.17 & 2.98 & 2.46 \\
\hline$C 1$ & ${ }^{12} C\left(d, p_{0}\right){ }^{13} C$ & 2.51 & 3.24 & 2.77 \\
\hline$N 6$ & ${ }^{14} N\left(d, p_{2}\right){ }^{15} N$ & 3.19 & 3.87 & 3.52 \\
\hline$N 5$ & ${ }^{14} N\left(d, p_{1}\right){ }^{15} N$ & 3.21 & 3.90 & 3.55 \\
\hline$N 4$ & ${ }^{14} N\left(d, \alpha_{2}\right){ }^{12} C$ & - & 4.46 & - \\
\hline N3 & ${ }^{14} N\left(d, \alpha_{1}\right){ }^{12} C$ & 3.83 & 6.68 & - \\
\hline$N 2$ & ${ }^{14} N\left(d, p_{0}\right){ }^{15} N$ & 8.16 & 8.63 & 8.57 \\
\hline$N 1$ & ${ }^{14} N\left(d, \alpha_{0}\right){ }^{12} C$ & 7.78 & 9.78 & 5.66 \\
\hline
\end{tabular}

Table 1: Calculated energy of the RBS step and the nuclear reactions of surface carbon, nitrogen and oxygen for the three experimental conditions used in this work. ${ }^{A} X\left(m, n_{p}\right)^{B} Y$ denotes the reaction of the ${ }^{A} X$ isotope with a $m$ particle, which produces the ${ }^{B} Y$ isotope in its $p$-excited state and $n_{p}$ particles. In the case of use of a Mylar foil to stop back-scattered deuterons, the RBS step does not exist in the spectrum. 


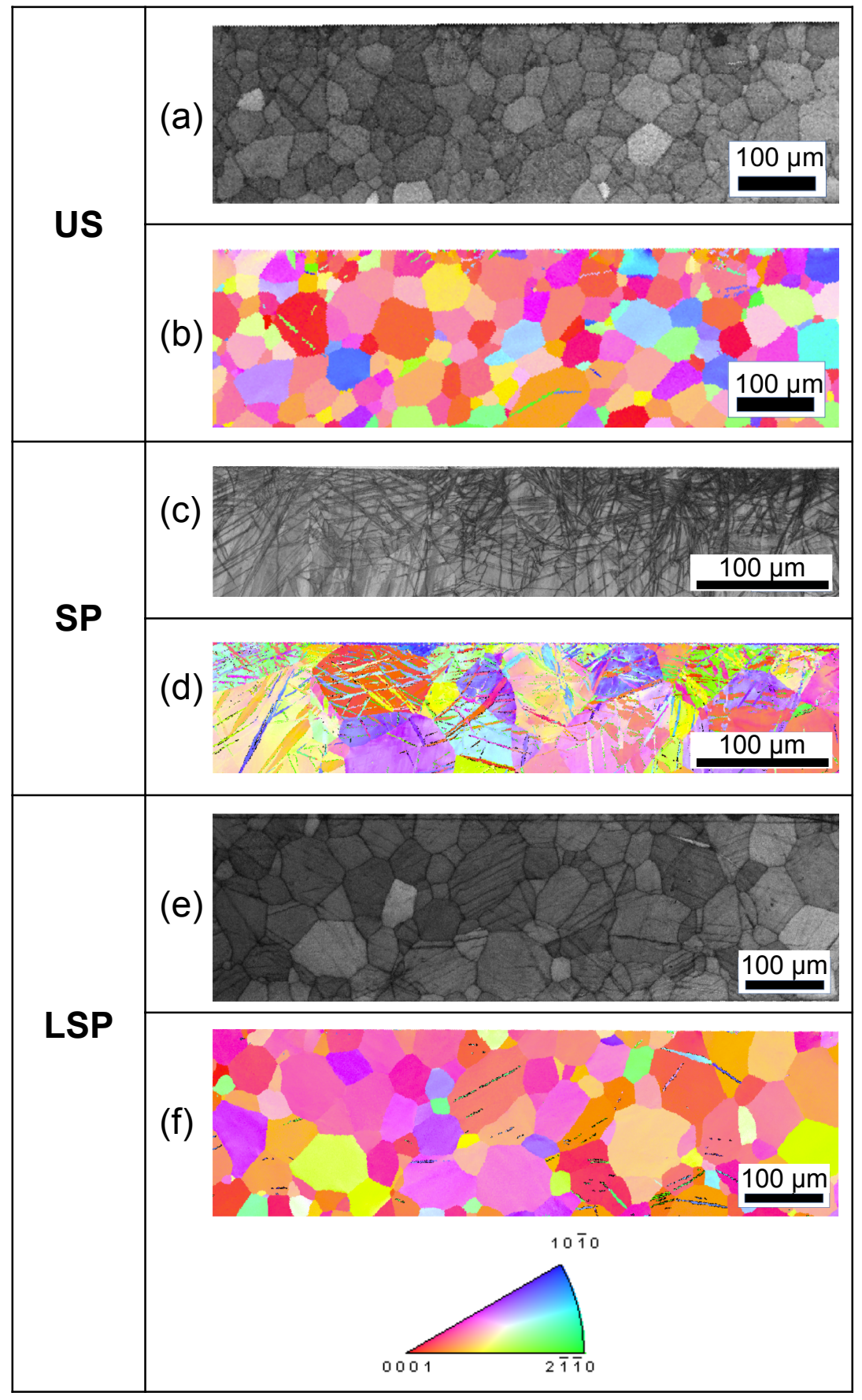

Figure 1: SEM-BSE (a,c,e) and EBSD (b,d,f) cross-section images obtained for US, SP and LSP samples before exposure to high temperature. 
show a strong impact of the treatment on the microstructure. A huge density of twins appears under the sample surface, mainly up to about $70 \mu \mathrm{m}$. The mean grain size is difficult to estimate in these conditions. The SP treatment increases the roughness of the samples [30] and introduces compression stresses [30] which can affect the chemical reactivity of pure titanium at high temperature. The LSP treatment induces the formation of a lower number of twins than the SP treatment. In this case, the twins spread several hundred of microns below the surface. So, the LSP treatment affects the whole thickness of the titanium plates used in this work. Cellard et al. [36] also reported this effect in LSP treated plates of Ti-17 alloy. The observed increase in hardness was mainly attributed to the presence of compressive residual stresses while the effect of cold work-hardening was small. In our case, the thickness of titanium plates was only $1 \mathrm{~mm}$, which leads to low compression stress.

\subsubsection{Chemical analysis of mechanically treated Ti surfaces}

The effects induced by SP and LSP treatments on the chemical composition at the top of the raw material were studied by IBA techniques. Figure 2 shows RBS-NRA spectra obtained from the surface of US, SP and LSP samples before high temperature exposure. The energy of the deuteron beam was $1.45 \mathrm{MeV}$. In the low energy range, for $\mathrm{E}<1.45 \mathrm{MeV}$, the spectra display the signal corresponding to backscattered deuterons (RBS spectra). In the high-energy range, for $\mathrm{E}>1.45 \mathrm{MeV}$, spectra show peaks corresponding to nuclear reactions (NRA spectra).

In the low energy range (Figure 2a) the RBS spectra of US, SP and LSP samples display a vertical step at $1.23 \mathrm{MeV}$ which matches the energy calculated for the scattering of a deuteron beam of $1.45 \mathrm{MeV}$ by titanium atoms (RBS-Ti in Table 1). For lower energies, the spectra display a flat plateau as expected for titanium plates. In this plateau, a contribution due to scattering by oxygen atoms at $0.88 \mathrm{MeV}$ (RBS-O in Table 1 ) is not observed for any sample. One can conclude that the native oxide layer of titanium which covers US samples is too thin to be detected by RBS, and that the possible oxidation induced by 
(a)

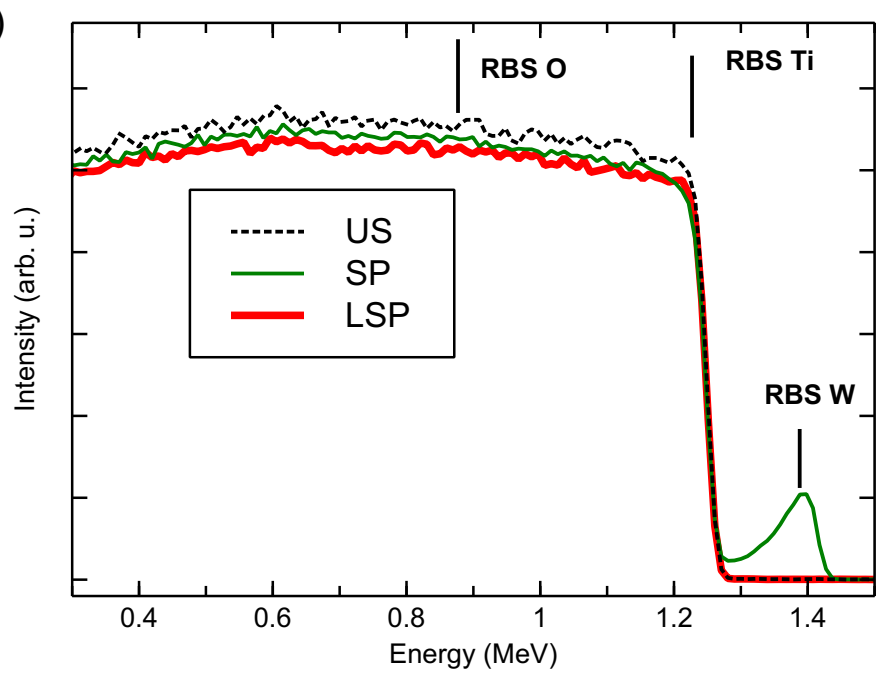

(b)

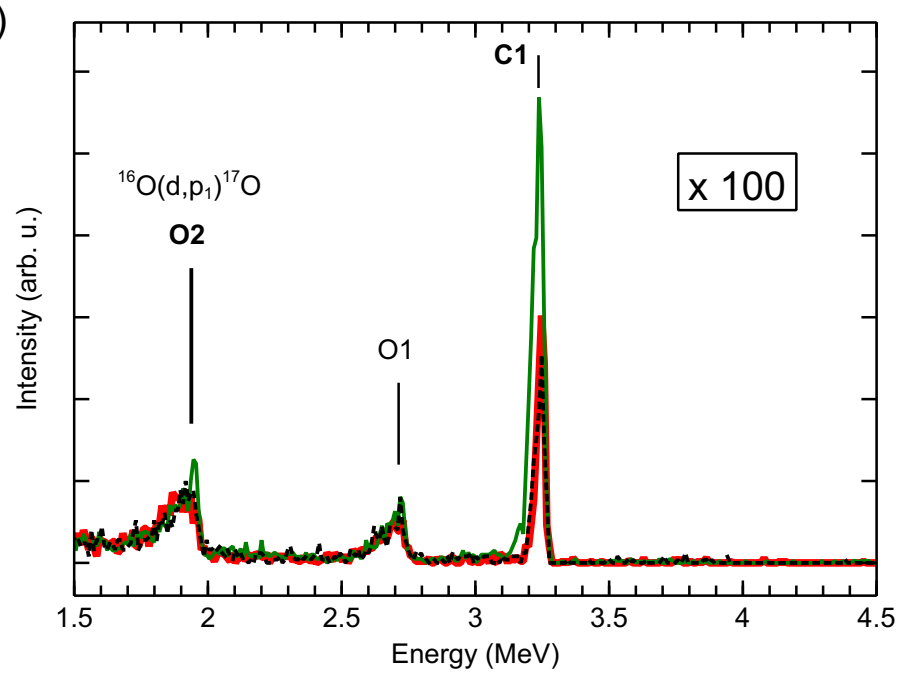

Figure 2: RBS-NRA spectra of US, SP and LSP samples before exposure to high temperature. Experimental conditions: deuteron beam energy: $1.450 \mathrm{MeV}$, detection angle: $170^{\circ}$ for backscattering and emitted protons and alpha particles, without annular Mylar foil. Vertical lines show the calculated position of nuclear reactions given in Table 1. 
SP and LSP treatments is below the detection limit. By contrast, the RBS spectrum of SP samples shows also a peak at $1.39 \mathrm{MeV}$ which can be assigned to backscattering of deuterons by tungsten (RBS-W in Table 1). This peak reveals the transfer of matter from the tungsten carbide balls used for the SP treatment to the surface of the titanium sample.

In the high-energy range $(\mathrm{E}>1.45 \mathrm{MeV})$, the NRA spectra of US, SP and LSP samples displayed three peaks that can be assigned to nuclear reactions involving oxygen and carbon. No peaks associated to nitrogen were found. The peaks placed at 1.94 and $2.71 \mathrm{MeV}$ can be assigned, respectively, to the reactions $O 2$ and $O 1$ of the ${ }^{16} \mathrm{O}$ isotope. The low intensity of these peaks confirms the small thickness of the native oxide layer covering the untreated samples, and the negligible oxidation induced by SP and LSP treatments. The sharp peak at $3.25 \mathrm{MeV}$ can be assigned to the reaction $C 1$ involving the ${ }^{12} C$ isotope. The intensity of this peak is higher for the SP sample which can be due to the surface treatment with WC balls. For the LSP treated samples, the heating induced by the laser is located in the extreme surface of the target and affects only the aluminium foil which protects it [16]. The heating of the aluminium foil can induce the pyrolysis of the adhesive layer and carbon pollution of the surface. However, the laser-shock peening can be considered as a purely mechanical treatment since no chemical reactions affect the titanium.

\subsection{Short-term high-temperature oxidation resistance}

\subsubsection{Oxidation kinetics}

Figure 3 shows the results of TGA experiments up to $10 \mathrm{~h}$ of exposure at $700{ }^{\circ} \mathrm{C}$ in dry air for US, SP and LSP samples. The SP treated titanium shows the lowest mass gain, only $60 \%$ of the value measured for US and LSP samples at $10 \mathrm{~h}$ exposure.

If oxidation is governed by diffusion, then the mass gain versus time can be fited to a pure parabolic function (eq.1):

$$
(\Delta m / S)^{2}=k_{p} \cdot t
$$



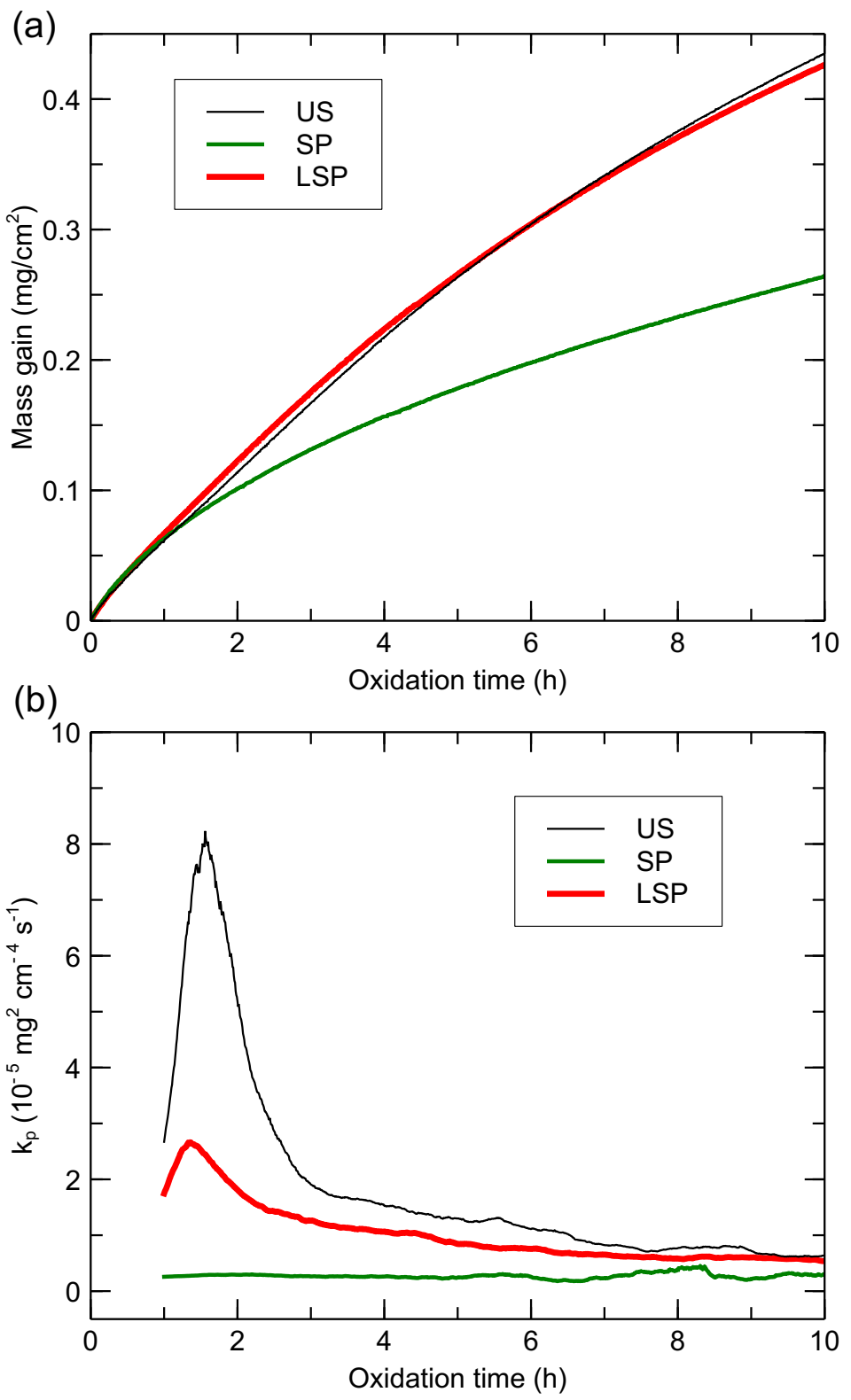

Figure 3: (a) Short-term mass gain as function of the time for US, SP and LSP samples at $700{ }^{\circ} \mathrm{C}$. (b) Instantaneous parabolic constant, $k_{p}$ [37] obtained by using a moving window of $2 \mathrm{~h}$ to fit the variation of the mass gain with the time. 
where $\Delta m / S$ is the mass gain per unit area at time $t$ and $k_{p}$ is the parabolic rate constant.

For the SP sample, the variation of the mass gain shows a nearly parabolic behaviour in the whole $0-10 \mathrm{~h}$ time range, which corresponds to a rate-limiting oxidation process given by oxygen diffusion through a dense and protective barrier [30]. For US and LSP samples the mass gain varies also as a nearly parabolic function of time beyond about $7 \mathrm{~h}$ of exposure to high temperature, but the variation is almost linear for lower oxidation times [16]. This behaviour corresponds to a rate-limiting oxidation process given by the oxide/metal interface reaction or can be a combination of several mechanisms.

After a transient time, the mass gain can be fitted with a complete parabolic function (eq.2) :

$$
t=A+B(\Delta m / S)+C(\Delta m / S)^{2}
$$

where A, B and C are fitting coefficients [37]. The evolution of the diffusion process with time at the early stages of the oxidation can be analysed by fitting the experimental curve in a sliding short time interval in order to calculate the instantaneous parabolic constant, $k_{p}=1 / C$, as defined by Monceau and Pierragi [37].

Figure $3 \mathrm{~b}$ shows the results obtained with a sliding interval of $2 \mathrm{~h}$. The value of $k_{p}$ remains nearly constant $\left(\sim 2.8 \times 10^{-6} \mathrm{mg}^{2} . \mathrm{cm}^{-4} \cdot \mathrm{s}^{-1}\right)$ for SP treated titanium. By contrast, it varies rapidly for US and LSP samples at the very beginning of the oxidation up to about $3 \mathrm{~h}$ of exposure to high temperature, and then it decreases slowly. These results suggest that the changes in microstructural and elemental composition of the surface induced by the SP treatment have a significant influence on the first stages of oxidation of pure titanium, while the effect of the LSP treatment is lower in this time range.

\subsubsection{SEM characterization along the cross-section}

Figure 4 displays cross-section SEM images of 5h-oxidized samples of untreated and mechanically treated titanium which show the oxides scale, the 
(a) US-5h

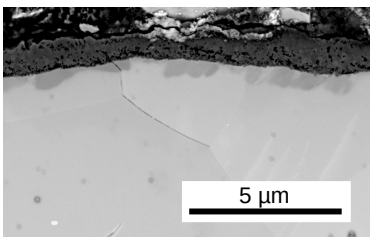

(b) SP-5h

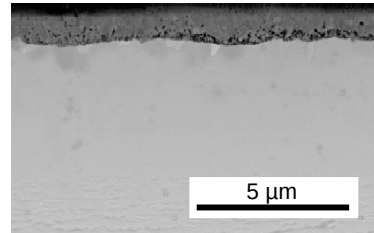

(b) LSP-5h

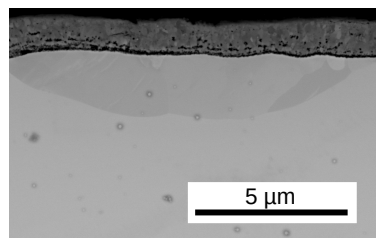

Figure 4: Cross-section SEM (BSE mode) views of 5h-oxidized samples of untreated (US-5h) and mechanically treated (SP-5h and LSP-5h) titanium. The oxide is at the top of the images.

interface and the metal substrate. One can remark oxide grains of the order of $200 \mathrm{~nm}$ in the body of the oxide scale, as well as darker and smaller grains close to the interface with the substrate. On the top of the metal substrate, a discontinuous layer of slightly darker gray grains suggests the insertion of a high concentration of light elements into the metal close to the oxyde/metal interface. Previous studies [17] have shown that oxygen diffuses on about $10 \mu \mathrm{m}$ deep under the oxide at $700{ }^{\circ} \mathrm{C}$ for an exposure time of $100 \mathrm{~h}$. Moreover, the insertion of nitrogen at the oxide/metal interface has been shown by IBA techniques in 100h-oxidized samples of titanium [17]. Here, EDS analysis has shown the presence of nitrogen in the slightly darker gray grains of the discontinuous layer on the top of the metal substrate. However, the small thickness of this layer, less than $1 \mu \mathrm{m}$, makes the quantitative analysis of its elemental composition by EDS hazardous. The results obtained by IBA techniques are given in section 3.2.4.

\subsubsection{Structural characterization of the scale}

The XRD patterns obtained in grazing incidence with an angle of $2^{\circ}$ for US, SP and LSP samples after oxidation during 5 and $10 \mathrm{~h}$ are given in Figure 5. The probing depth of the X-ray beam for titanium was estimated to about $3 \mu \mathrm{m}$ for normal incidence [38], and to about $0.4 \mu \mathrm{m}$ for an incidence angle of $2^{\circ}$.

Figure 5 shows for untreated and mechanically treated titanium the formation of titanium dioxide mainly crystallized in the rutile phase $\left(\mathrm{R}-\mathrm{TiO}_{2}\right)$. The intensity of the peaks assigned to rutile is smaller for 5h-oxidized SP treated 
titanium compared to US-5h and LSP-5h samples (Figure 5.b). Small XRD peaks assigned to the anatase phase $\left(\mathrm{A}-\mathrm{TiO}_{2}\right)$ are observed only for oxidized SP samples.

For the three samples, several XRD peaks were assigned to a titanium oxynitride solid solution $\alpha-\operatorname{Ti}(\mathrm{N}, \mathrm{O})$. Moreover, several small peaks were assigned to $\mathrm{Ti}_{2} \mathrm{~N}$ for SP-5h and LSP-5h even if they were very small in this latter case. They are absent for US-5h. For a longer oxidation process of $10 \mathrm{~h}$, the peaks assigned to this nitride phase are still present in the XRD pattern of SP-10h, but they were not detected for LSP-10h.

Extending the oxidation time up to $100 \mathrm{~h}$ leads to XRD patterns (not shown) displaying only the peaks of titanium dioxide as reported in a previous work [17]. NRA analysis of the cross-section of 100-h oxidized samples revealed the formation of a nitrogen-rich layer at the oxide/metal interface. This layer was continuous in oxidized SP and LSP treated samples, while it was discontinuous in untreated titanium.

The results reported in Figure 5 show the insertion of nitrogen in the first hours of the oxidation process with the formation of titanium nitride and oxynitride. After $10 \mathrm{~h}$ at $700{ }^{\circ} \mathrm{C}$, the thickness of the oxide layer can prevent detecting a nitrogen-rich layer formed at the oxide/metal interface. A nitride phase was only detected for SP-10, which displays a lower mass gain compared to US-10h and LSP-10h, and has a thinner oxide layer.

Finally, several peaks assigned to $\mathrm{WO}_{3}$ confirmed the matter transfer from the balls used for the SP treatment to the sample surface. The intensity of these peaks strongly reduces after $10 \mathrm{~h}$ at $700{ }^{\circ} \mathrm{C}$ (Figure 5b). This effect can be explained by the volatility of tungsten trioxide above $600{ }^{\circ} \mathrm{C}[39]$. So, the presence of tungsten at the sample surface after the SP treatment cannot provide any protective benefit against oxidation of titanium after several hours of high temperature. 
(a)

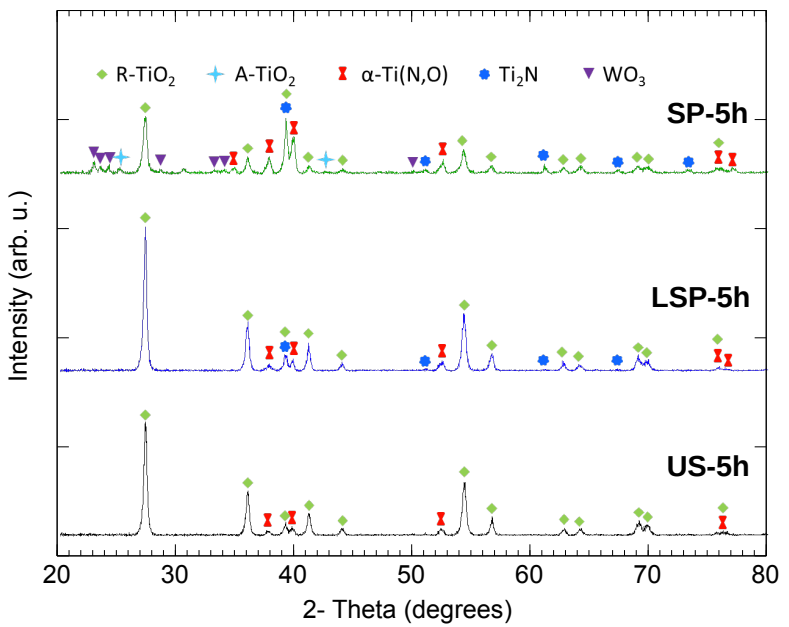

(b)

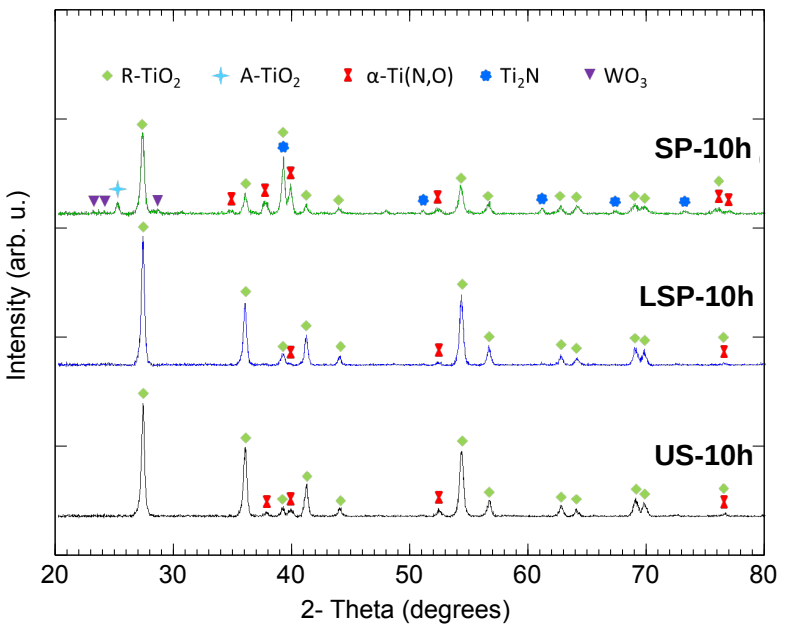

Figure 5: Grazing incidence $\left(2^{\circ}\right)$ X-ray diffraction patterns of US, SP and LSP samples after high temperature oxidation for: (a) $5 \mathrm{~h}$, and (b) $10 \mathrm{~h}$. The assignment of the experimental peaks is given by labels corresponding to $\mathrm{TiO}_{2}$ in rutile (R) and anatase (A) phases, titanium oxynitride $\alpha-\mathrm{Ti}(\mathrm{N}, \mathrm{O}), \mathrm{Ti}_{2} \mathrm{~N}$ and $\mathrm{WO}_{3}$. 


\subsubsection{Analysis of the elemental composition of the oxidation layer}

The elemental composition, of the oxidation layer was analysed by IBA techniques by using a deuterons beam of $1.45 \mathrm{MeV}$ perpendicularly to the sample surface. The thin oxidation layer formed after $5 \mathrm{~h}$ of exposure at $700{ }^{\circ} \mathrm{C}$ does not prevent the deuterons beam from penetrating the oxide layer and reaching the metal. The spectra obtained for 5h-oxidized samples of untreated and mechanically treated titanium are given in Figure 6.

For all the samples, the spectra show in the low energy range, $\mathrm{E}<1.45 \mathrm{MeV}$, the RBS signals due to titanium and oxygen. Moreover, the peak assigned to RBS-W is still observed at $1.39 \mathrm{MeV}$ for the SP-5h sample as before exposure to high temperature. In the $1.27-1.21 \mathrm{MeV}$, the signal rise due to deuterons scattered by titanium at the sample surface is superimposed for all three types of samples. For non-oxidized samples, the RBS spectra displayed, below $1.21 \mathrm{MeV}$, a plateau extending up to the lowest energies, but this is not the case for oxidized samples due to contribution of the oxide layer.

For a homogeneous oxide layer formed on top of the metal, the RBS spectra should remain nearly constant below $1.2 \mathrm{MeV}$ up to a signal rise due to deuterons back-scattered by oxygen atoms. The width of this intermediate plateau is a function of the thickness of the oxide layer. However, the spectra of US-5h, SP$5 \mathrm{~h}$ and LSP-5h show a complex variation in the 0.9-1.21 MeV range composed by a plateau and a progressive increase of the signal. The larger plateau is observed for the LSP-5h sample, which is in agreement with the higher mass gain measured for the LSP-5h sample compared to US-5h and SP-5h (Figure 3a). The progressive increase of the RBS signal which follows the intermediate plateau suggests the diffusion of oxygen in the metal under the oxide layer. The differences observed in the shape of the RBS spectrum in the 0.7-0.9 MeV range (RBS-O) are also related to the thickness of the oxide layer and the difussion of oxygen in the metal.

In the high energy range of Figure 6, $\mathrm{E}>1.45 \mathrm{MeV}$, the NRA spectra show the oxidation of the samples, but also the presence of nitrogen. The $C 1$ peak 

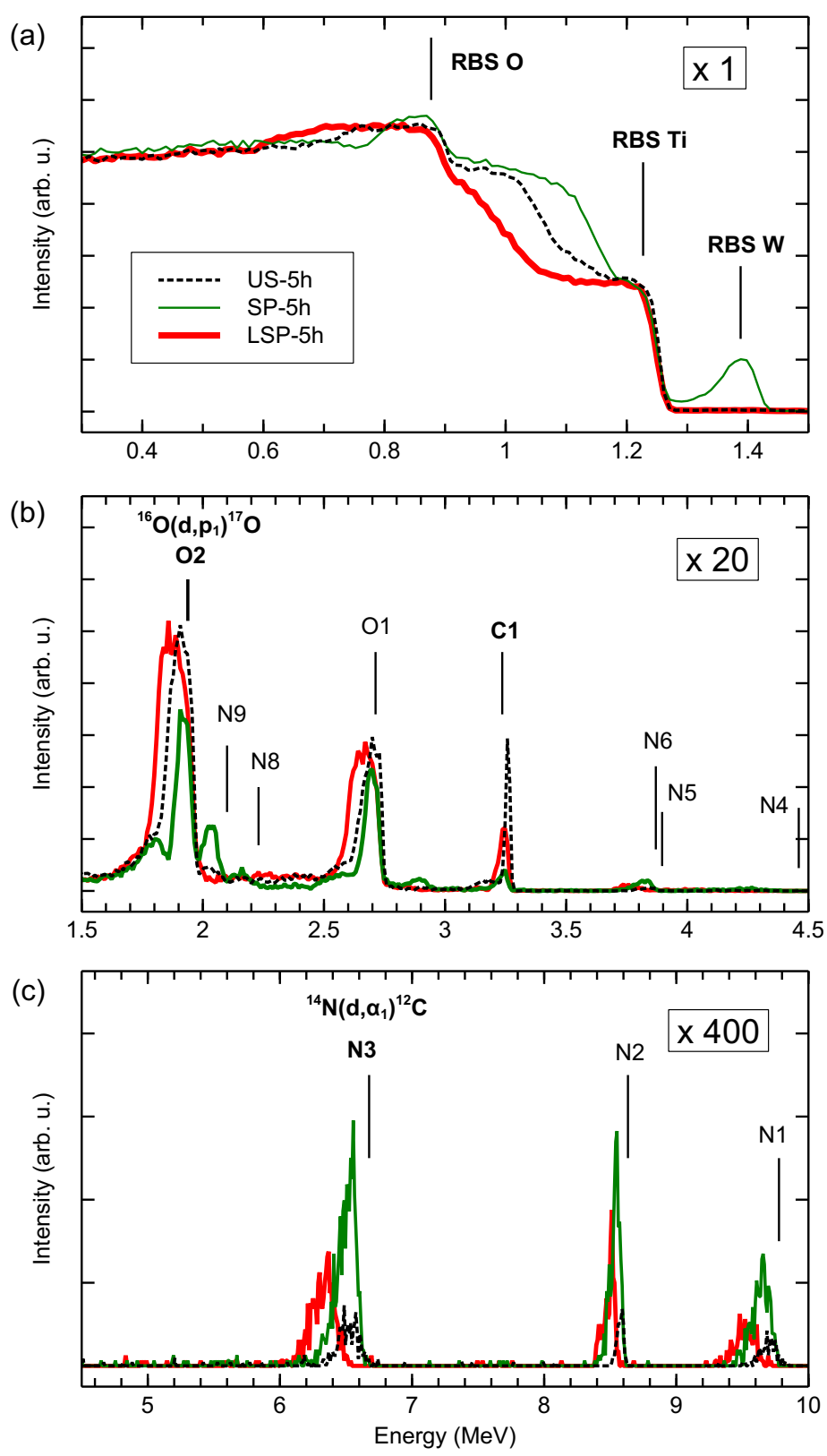

Figure 6: RBS-NRA spectra of untreated and mechanically treated titanium oxidized for $5 \mathrm{~h}$ (US-5h, SP-5h and LSP-5h samples, respectively). Experimental conditions: deuteron beam energy: $1.450 \mathrm{MeV}$, detection angle: $170^{\circ}$, without Mylar foil to cover the detector. Ordinate scales expanded by factors x 30 in (b) and x 600 in (c). Vertical lines show the calculated position of nuclear reactions taking place on the sample surface (Table 1). 
of carbon is also detected here but its relative intensity with respect to the $O 1$ and $O 2$ peaks of oxygen is lower compared to non-oxidized samples (Figure 2). Moreover, the intensity of the peaks of oxygen is higher for the US-5h and LSP$5 \mathrm{~h}$ samples compared to the SP-5h one, which agrees with the higher mass gain shown in Figure 3a).

The presence of nitrogen is shown by several NRA peaks. In spite of their low intensity, they can be easily identified in the highest energy range, $3.5<\mathrm{E}<10.0$ $\mathrm{MeV}$, due to the absence of possible interference from NRA peaks of oxygen and carbon in this energy range. Contrary to the NRA peaks of oxygen, the NRA peaks of nitrogen in Figure 6c are shifted to lower energies compared to the calculated energies for reactions occurring at the sample surface (Table 1). This shift corresponds to the loss of energy of the particles produced by the nuclear reactions deeper under the surface in their pathway going up to the sample surface. The insertion depth of nitrogen corresponding to the observed shift of NRA peaks was roughly calculated under the assumption that the particles pass through an oxide layer composed of rutile (density $4.3 \mathrm{~g} / \mathrm{cm}^{3}$ ). The values obtained were $0.40 \mu \mathrm{m}$ for US-5h and SP-5h, and $1.10 \mu \mathrm{m}$ for LSP-5h.

To go further in the analysis of IBA results, the experimental spectra of 5h-oxidized US, SP and LSP samples (Figure 6) have been simulated using the SIMNRA software (Figures S2, S3 and S4). This approach provides additional quantitative data on altered layers. Although the whole signals cannot be accurately reproduced due to a lack of knowledge of cross sections (probability of occurrence) of peculiar nuclear reactions, most information on light elements concentration and depth position appear however several times in the spectra from the signals of joint nuclear reactions.

Calculated spectra (Figures S2, S3 and S4) were obtained considering a succession of stratified layers, from the top of the oxide layer to the substrate. The outer layer was composed of titanium dioxide, $\mathrm{TiO}_{2}$. The inner layer was a diffusion zone of oxygene and/or nitrogen. In between, different compositions as titanium nitride $\left(\mathrm{Ti}_{2} \mathrm{~N}\right)$ and/or titanium oxinitride layers $\left(\mathrm{TiO}_{x} \mathrm{~N}_{y}\right)$ were considered from the modelling. The thickness of the different layers were tuned to 
fit the experimental spectra. Figure 7 shows a schematic view of the multilayer structure optimized for the three 5 h-oxidized samples. The indicated values for these compounds are only rough compositions since altered layers present slight lateral heterogeneities, both in composition and thickness.

The thickness of the top layer of $\mathrm{TiO}_{2}$ is $0.9 \mu \mathrm{m}$ for the untreated sample, $0.5 \mu \mathrm{m}$ for SP-5h and $1.3 \mu \mathrm{m}$ for LSP-5h. This results are consistent with the values of the instantaneous $k_{p}$ given in Figure 3.

For the three kinds of samples, a middle layer of $\mathrm{Ti}_{2} \mathrm{~N}$ provides the best fit of the experimental spectra. This is in agreement with the results of XRD which show small peaks assigned to $\mathrm{Ti}_{2} \mathrm{~N}$ for SP-5h. For LSP-5h, these peaks were quite smaller, and they are negligible for US-5h. The lower thickness of the oxide layer for SP-5h and the higher thickness of the $\mathrm{Ti}_{2} \mathrm{~N}$ layer $(0.6 \mu \mathrm{m})$ can explain the easier detection of $\mathrm{Ti}_{2} \mathrm{~N}$ in this case. For the US-5h and LSP-5h samples, the thickness of the $\mathrm{Ti}_{2} \mathrm{~N}$ layer is $0.4 \mu \mathrm{m}$. Very recently, Dupressoire et al. [27] observed also by atom probe tomography the formation of an interfacial titanium oxynitride and nitride layer in 1000-h oxidized Ti6242S at $650{ }^{\circ} \mathrm{C}$. Below the $\mathrm{Ti}_{2} \mathrm{~N}$ layer, oxygen diffusion goes up to about $0.2 \mu \mathrm{m}$ for US-5h and $0.7 \mu \mathrm{m}$ for SP-5h, while for LSP-5h it is found nitrogen diffusion over about $0.5 \mu \mathrm{m}$. This result is in agreement with the important shift towards lower energies of the NRA peaks of nitrogen for LSP-5h (Figure 6) with respect to the expected position if nitrogen was present at the surface of the sample (Table 1 ), which reflects the depth of the insertion of nitrogen. This result is a key point to explain the higher oxidation resistance of LSP treated titanium for medium (100 h) [16] and long ( $3000 \mathrm{~h})$ exposure to high temperature.

The multilayer structure of the oxidation layer of 5h-oxidized samples obtained by IBA is supported by the results obtained by SEM observations along the cross-section and EDS analysis. The LSP treatment favours the insertion of nitrogen at the top of the metal from the first hours of the oxidation, which acts as a barrier to the diffusion of oxygen. The SP treatment does not provide the same effect which penalizes its long-term oxidation resistance. 


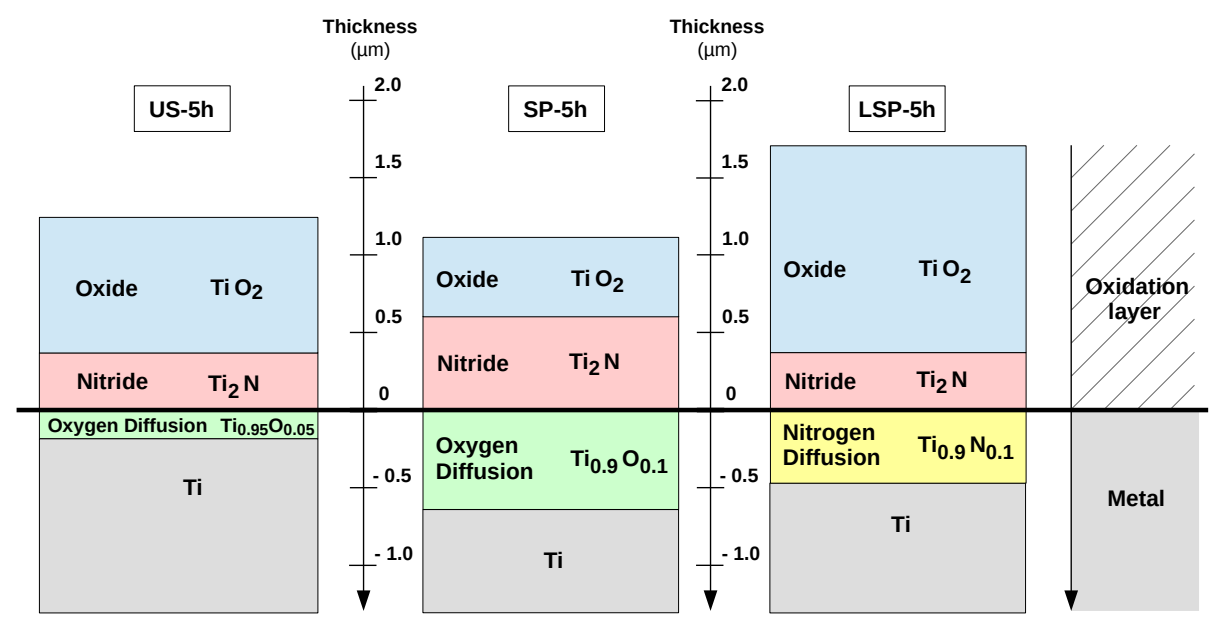

Figure 7: Schematic multilayer structure of the oxidation layers formed in SP and LSP treated samples after $5 \mathrm{~h}$ at $700^{\circ} \mathrm{C}$. The composition and the estimated thickness of the different layers are given by the modelling of the NRA spectra of SP-5h and LSP-5h samples (Figure 6).

\subsection{Long term high temperature oxidation resistance}

\subsubsection{Oxidation kinetics}

The mass gain curves for long oxidation tests $(3000 \mathrm{~h})$ are shown in Figure 8a. The most noteworthy feature is the excellent behaviour of LSP treated samples compared to SP and untreated samples which show break-away oxidation followed by spallation of the oxide layer after about 1700 hours. Moreover, the increase of the mass gain for US and SP samples seems to become nearly linear as a function of the time after about $700 \mathrm{~h}$. This suggests that the oxygen flow reaching the metallic substrate becomes roughly constant, which would be the case if the oxide layer is cracked and the thickness of the remaining uncracked oxide layer is nearly constant.

For LSP treated titanium, the mass gain after an exposure time of $3000 \mathrm{~h}$ was of $6.7 \mathrm{~g} / \mathrm{cm}^{2}$. Cross-section SEM images given in section 3.3 .3 show that the oxide layer remains adhered to the substrate for the LSP-3000h sample.

The formation of a protective oxide layer against oxidation would provide a parabolic oxidation kinetics [40]. To confirm this behaviour, the mass main ver- 
sus $\mathrm{t}^{1 / 2}$ has been plotted in Figure $8 \mathrm{~b}$. The figure shows a parabolic oxydation kinetics up to around $400 \mathrm{~h}$ for the US and LSP samples, and up to about $200 \mathrm{~h}$ for the SP treated sample. The calculated $\mathrm{k}_{p}$ values are $9.9,2.5$ and $3.0 \times 10^{-6}$ $\mathrm{mg}^{2} \cdot \mathrm{cm}^{-4} \cdot \mathrm{s}^{-1}$ for the US, SP and LSP samples, respectively.

For longer oxidation times, the oxidation kinetics is more or less modified according to the mechanical treatment. For LSP treated titanium, the $\mathrm{k}_{p}$ value corresponding to a parabolic fit in the $400-2200 \mathrm{~h}$ range increases to $0.8 \times 10^{-5}$ $\mathrm{mg}^{2} \cdot \mathrm{cm}^{-4} \cdot \mathrm{s}^{-1}$. The LSP treatment provides effective protection against high temperature oxidation for long exposure times.

For SP and US samples, the oxidation kinetics changes more than for the LSP sample. The number of experimental points is too low to correctly analyze the oxidation kinetics, but a tentative fitting to a parabolic law gives a $\mathrm{k}_{p}$ increase up to 1.9 and $8.8 \times 10^{-5} \mathrm{mg}^{2} \cdot \mathrm{cm}^{-4} \cdot \mathrm{s}^{-1}$ for the SP and US samples, respectively.

\subsubsection{Cross-section microhardness profile of 3000h-oxidized samples}

The changes of the mechanical properties of titanium due to the diffusion of oxygen and nitrogen in the metal during the oxidation process have been studied by microhardness measurements along cross sections of the three samples. The results are given in Figure 9 versus the depth from the oxide/metal interface.

All the samples show a strong hardening near to the oxide/metal interface reaching around $850 \mathrm{HV}$, which can be explained by the diffusion of oxygen and/or nitrogen at high temperature. Below this interface, the in-depth hardness decreases for all the samples, but only the LSP treated sample reaches the lowest value of $112 \mathrm{HV}$ which remains constant at least until a depth of $600 \mu \mathrm{m}$. This value agrees with the microhardness reported in ref. [17] for the core of 100-h oxidized samples of LSP treated pure titanium. This suggests that oxygen diffusion is negligible in the core of LSP-3000h samples. However, the progression in depth of the alpha-case with the increase of the oxidation time is clearly shown by the hardness profiles. The lowest microhardness value, 112 $\mathrm{V}$, is reached at about $80 \mu \mathrm{m}$ below the oxide/metal interface for $100 \mathrm{~h}$-oxidized 

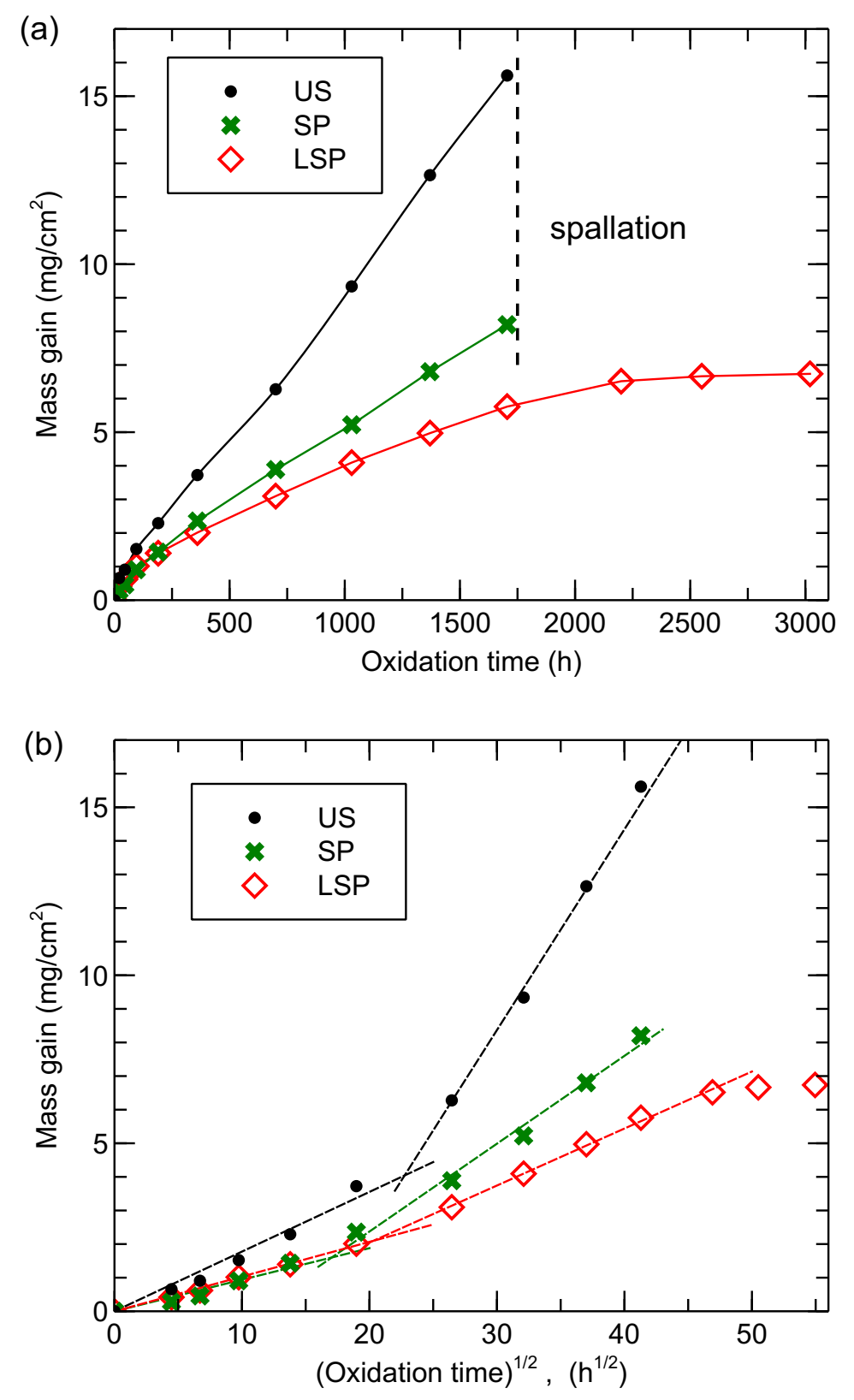

Figure 8: (a) Long-term mass gain at $700{ }^{\circ} \mathrm{C}$ as function of the time for US, SP and LSP samples, (b) fitting to a parabolic law. 
samples, while it is observed at nearly $200 \mu \mathrm{m}$ for $3000 \mathrm{~h}$-oxidized samples.

For untreated and SP treated titanium the microhardness in the core of oxidized samples increases from $112 \mathrm{HV}$ to $215 \mathrm{HV}$ by increasing the oxidation time from 100 [17] to $3000 \mathrm{~h}$. This can be explained by the diffusion of oxygen coming from both sides of the sample, which has reached the whole thickness of the Ti plates in the case of 3000h-oxidized samples [41]. The thickness of the remaining metal is about $800 \mu \mathrm{m}$, which makes the minimum hardness to be found at about $400 \mu \mathrm{m}$ below the oxide/metal interface. The concentration of oxygen in the core of US-3000h and SP-3000h samples has been estimated assuming the following hypothesis: i) US, SP and LSP 3000h-oxidized samples have the same thermal history, ii) the hardness in the core of oxygen-free 3000hoxidized samples is $112 \mathrm{HV}$, iii) the possible differences in grain size according to the mechanical treatment have a negligible effect on the hardness of 3000hoxidized samples, $i v$ ) the hardness increase is proportional to the quantity of oxygen dissolved into the titanium lattice as nitrogen is present in much lower quantities than oxygen and thus participate less to the hardening of the material, $v$ ) the hardness at the metal/oxide interface corresponds to oxygen-saturated titanium, i.e. containing 33 at.\% of oxygen, and its value can be estimated about $1000 \mathrm{HV}$ by extrapolation of the experimental microhardness profiles. With these assumptions, the hardness at the core of US-3000h and SP-3000h samples corresponds to a concentration of oxygen of about 4 at.\%. This estimated value will be compared further with the concentration measured by NRA.

\subsubsection{Structure of 3000h-oxidized samples along the cross-section}

Cross-section SEM images of 3000h-oxidized samples of untreated and mechanically treated titanium. The images (Figure 10) were recorded in backscattering electrons mode (BSE). The oxide layer becomes stratified and flakes off after about $1700 \mathrm{~h}$ of exposure at a temperature of $700{ }^{\circ} \mathrm{C}$ for US and SP samples. Figures 10a and 10b show the oxide layer that remains on top of the titanium after 3000 h-oxidation. Its thickness is higher than $100 \mu \mathrm{m}$. Lefort et al. [22] reported also stratification and spallation of the oxide scale when the 


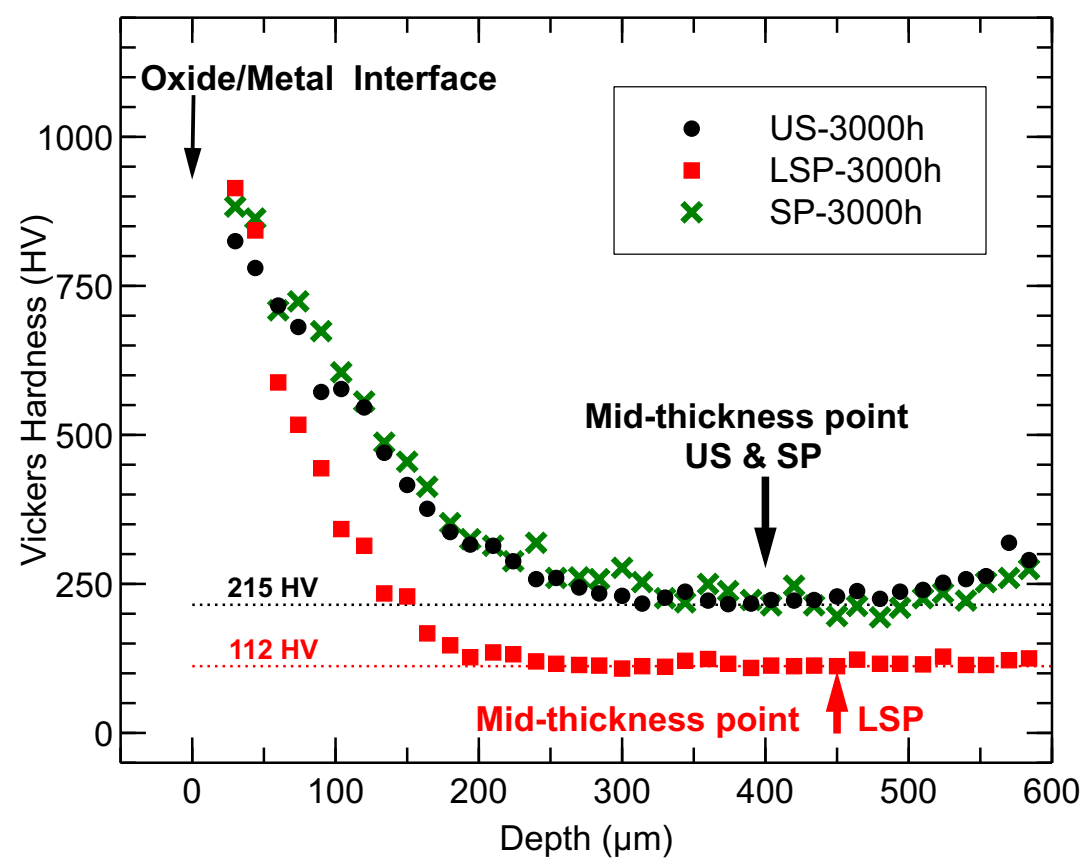

Figure 9: Micro-hardness profiles along the cross-section of the samples US-3000h, SP-3000h and LSP-3000h. The interface between the surface oxidation layer and the metal was taken as the origin for the in-depth distance. The depth value corresponding to the point at midthickness of the metal substrate is indicated by arrows for US and SP samples (in black) and for LSP sample (in red). Note: Two-side SP and LSP treatments were done on $1 \mathrm{~mm}$ thick Ti plates. 
thickness of the oxide scale exceeds about $10 \mu \mathrm{m}$. Stratification and spallation of the oxide scale provides a larger flow of oxygen to the inner layers of the scale. Then, the nitrogen-rich layer located at the oxide/metal interface can be gradually replaced by titanium dioxide due to the greater thermodynamic stability of titanium oxides compared to nitrides, as given by the corresponding Gibbs free energies of formation (Table S1).

Figures 10d and 10e show high magnification views of the oxide/metal interface for US-3000h and SP-3000h samples. The images show that the oxide layer adheres poorly to the metal substrate. No traces of darker layer which could be due to a nitrogen-rich layer located at this interface, as the one observed in Figure 4 for 5h-oxidized samples, can be observed here.

Unlike untreated and SP-treated titanium, it was not observed spallation of the oxide scale for LSP treated samples. Figure 10c shows an unstratified and adherent oxide layer. Its thickness is only $\sim 40 \mu \mathrm{m}$, which is agrees with the smaller mass gain measured for LSP-3000h compared to US-3000h and LSP3000h. Figure 10f shows a high-magnification view of the metal/oxide interface of the LSP-3000h sample which confirms the good adhesion of the oxide layer to the metal substrate. The magnification has been increased up to $\mathrm{x} 20,000$ in the inset of Figure 10f. It clearly shows a thin layer of darker grains at the top of the metal substrate, similar to the one observed for 5h-oxidized samples but with a lower thickness. This layer was not observed for US-3000h and SP-3000h samples. Cross-section analysis by IBA are given in next section to investigate the elemental composition of this layer and to detect the possible presence of nitrogen.

The cross-section of 3000h-oxidized samples was also analysed by Raman spectroscopy (Figure 11). In all the cases, the recorded Raman spectra showed only the characteristic bands of the rutile phase of $\mathrm{TiO}_{2}$ (Figure S6). The integrated intensity of these bands was used for mapping the spatial distribution of rutile in the cross-section of the 3000h-oxidized samples, as given in Figure 11 together with optical micrographs of the analysed areas.

The stratification of the oxide scale is clearly observed for the SP-3000h 
(a) US-3000h

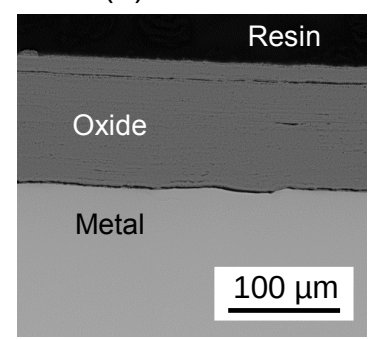

(d) US-3000h

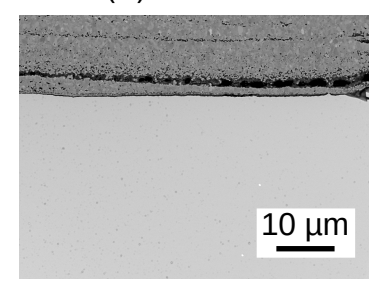

(b) SP-3000h

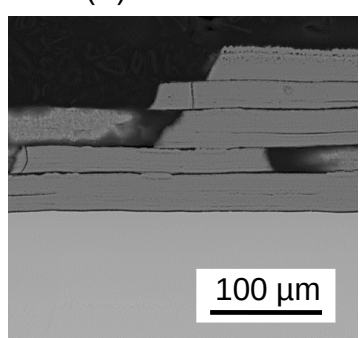

(e) SP-3000h

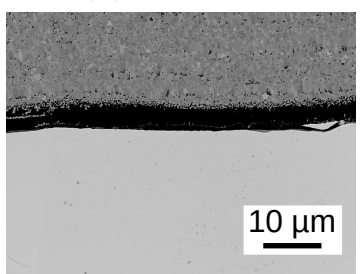

(c) LSP-3000h

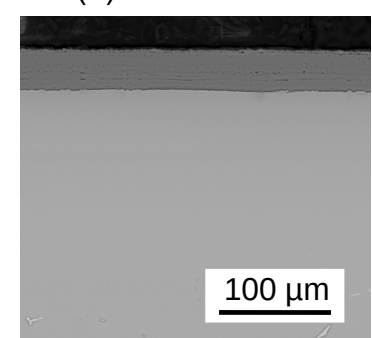

(f) LSP-3000h

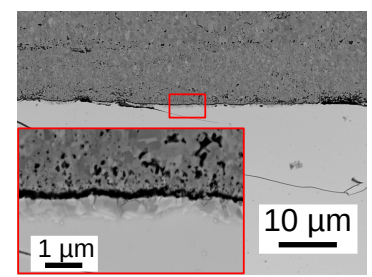

Figure 10: SEM (back-scattered electrons) cross-section views of the samples US-3000h (a,d), SP-3000h (b,e) and LSP-3000h (c,f) obtained in low (a,b,c) and high (d,e,f) magnifications. The oxide is at the top of the images.

US-3000h

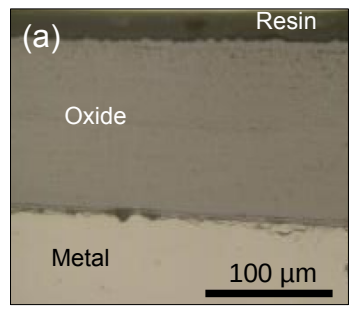

\section{(d)}

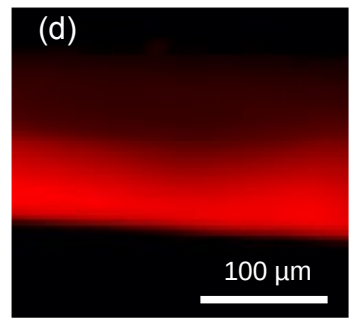

SP-3000h

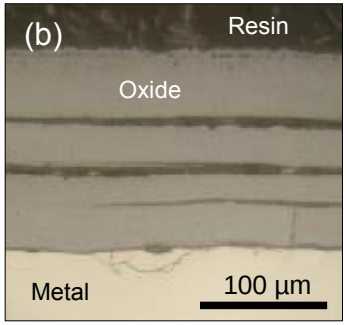

(e)

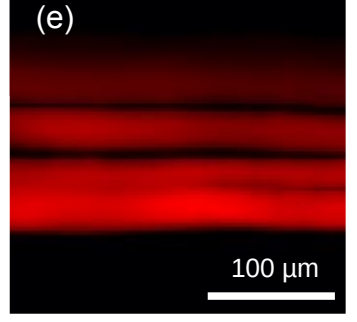

LSP-3000h

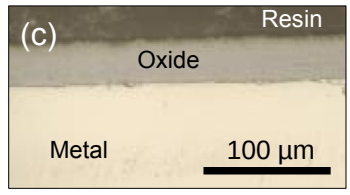

(f)

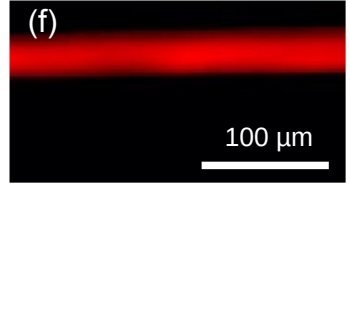

Figure 11: Optical cross-section micrographs of the US-3000h, SP-3000h and LSP-3000h samples, and Raman spectroscopy map showing the spatial distribution of rutile. 
sample. For the US-3000h sample, despite the absence of stratification in the analysed zone, the intensity of the rutile bands varies along the cross-section of the oxide layer. It is higher and nearly homogeneous in the inner part of the oxide layer, and it decreases in its outer part. Similarly, the Raman intensity is lower at the top of the oxide layer for the SP-3000h sample. This effect can be due to a lower compactness of titanium dioxide in the outer part of the oxide scale. Unlike untreated ans SP treated titanium, the intensity of the rutile bands for the LSP-3000h sample (Fig. $11 \mathrm{f}$ ) is nearly homogeneous in depth through the whole oxide scale, which shows the formation of a compact layer of rutile.

\subsubsection{Cross-section analysis of the elemental composition of 3000h-oxidized samples}

The elemental composition along the cross-section of 3000h-oxidized samples of untreated and mechanically treated Ti was analysed by IBA in scanning mode. First, the energy of the deuteron beam was fixed at $0.92 \mathrm{MeV}$ for a better detection of oxygen [42]. The goal was to study the diffusion of oxygen in the metal under the oxide layer. So, the analysed area $\left(300 \times 400 \mu \mathrm{m}^{2}\right)$ was taken from about $25 \mu \mathrm{m}$ above the oxide/metal interface to about $350 \mu \mathrm{m}^{2}$ deep in the metal underneath it. The NRA spectra obtained within this experimental conditions for US-3000h, SP-3000h and LSP-3000h samples are given in Figure S5a. The nuclear reactions $O 1$ and $O 2$ of the ${ }^{16} O$ isotope (Table 1) were used for mapping the spatial distribution of oxygen in the scanned area. The nuclear reaction $C 1$ of ${ }^{12} C$ was used for mapping the distribution of carbon which is mainly found in the epoxy resin used to coat the samples during the preparation of the cross sections. Several nuclear reactions of ${ }^{14} N$ were also detected, but their intensity was too small to analyse the spatial distribution of nitrogen.

Figure 12 displays the spatial distribution of oxygen and carbon in the cross section of US-3000h, SP-3000h and LSP-3000h oxidized samples. The oxidation

layer is placed in the top of the analysed area. A narrow strip of carbon is observed at the oxide/metal interface mainly for the US-3000h and SP-3000h 


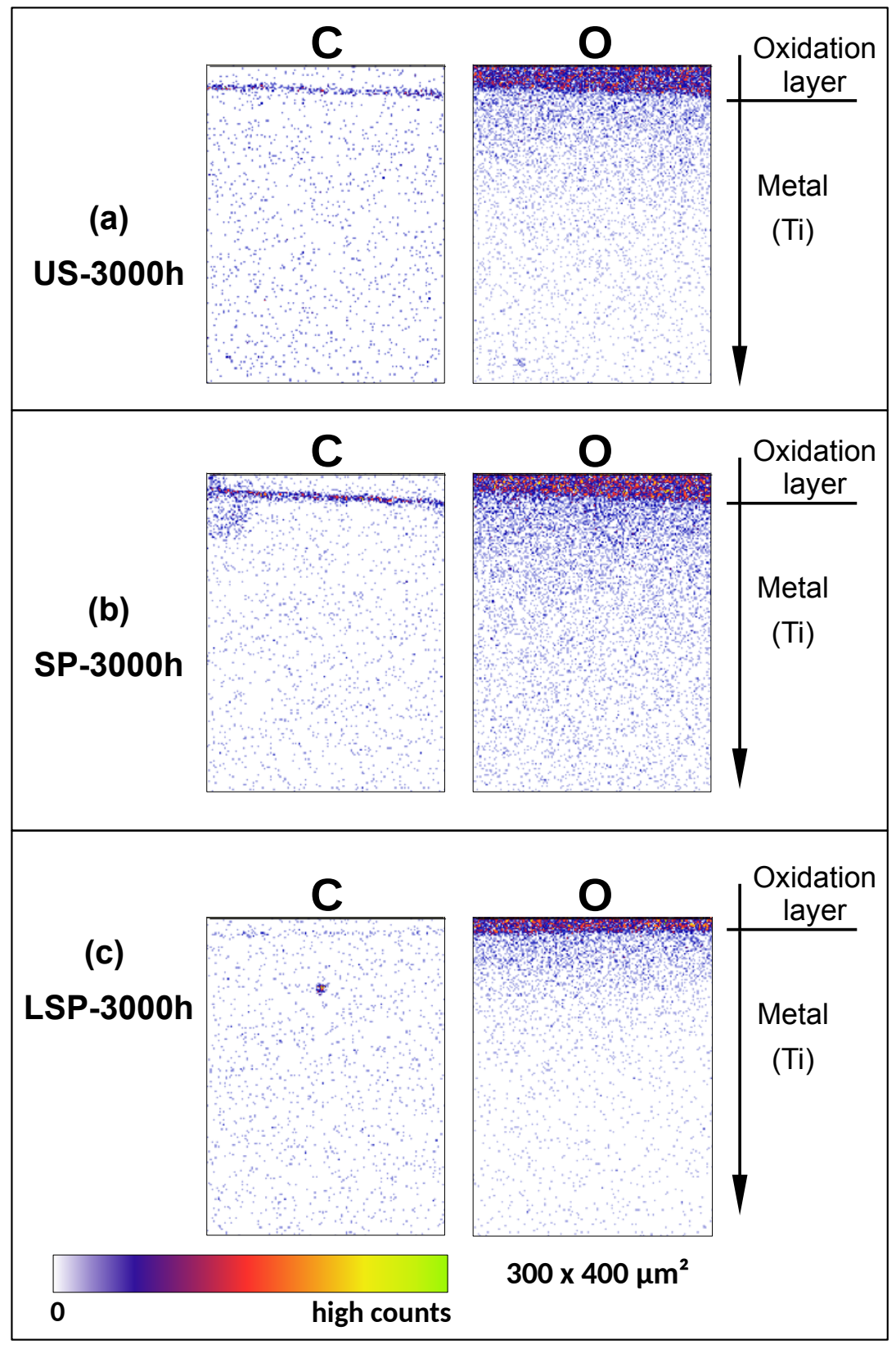

Figure 12: NRA maps $\left(300 \times 400 \mu \mathrm{m}^{2}\right)$ displaying the spatial distribution of the isotopes ${ }^{16} \mathrm{O}$ and ${ }^{12} C$ in the cross-section of the samples US-3000h, SP-3000h and LSP-3000h. Experimental conditions: deuteron beam at $0.92 \mathrm{MeV}$, detection angle of $170^{\circ}, 23 \mu \mathrm{m}$ thick annular Mylar foil. Nuclear reaction peaks: ${ }^{16} O\left(d, p_{1}\right){ }^{17} O$ for oxygen and ${ }^{12} C\left(d, p_{0}\right){ }^{13} C$ for carbon. 
samples. This can be due to pollution of the oxide/metal interface during the polishing process. Indeed, the difference of hardness between the oxide and the metal can lead, during the polishing, to the formation of a small step at the interface. Some debris from the resin used to coat the specimens could also be inserted in this area.

The highest signal of oxygen corresponds to the oxide layer. Underneath, a gradient of oxygen concentration runs on several hundreds of micrometres which clearly shows the diffusion of oxygen in the metal under the oxide layer. The in-depth variation of the concentration of oxygen was calculated adding line by line the data plotted in Figure 12 in order to reduce the signal-to-noise ratio. The results are shown in Figure 13. The concentration of oxygen in the scale was fixed considering that it is composed of stoichiometric titanium dioxide. The results (Figure 13) show the influence of the mechanical treatment applied to titanium on the diffusion of oxygen in the metal. The SP treated sample shows the highest concentration of oxygen, around 25\%, just under the oxide/metal interface, while the concentration is around $20 \%$ for LSP treated and untreated titanium. The SP treated sample shows also the highest concentration of oxygen at the core of the sample, around 2.3 at.\%, while the concentration of oxygen is around 1.4 at.\% for the US-3000h sample, and only $0.8 \%$ for LSP treated titanium for a depth around $150 \mu \mathrm{m}$ under the oxide/metal interface. This shows that the core of the metal is nearly oxygen-free for the LSP-300h samples, which is not the case for untreated and SP treated titanium. This results agree with the micro-hardness profiles measured along the cross-section of these samples and the estimated concentrations of oxygen. This result is of major importance because it demonstrates that the laser-shock peening is an efficient treatment to reduce the diffusion of oxygen towards the core of the material and then, to reduce the induced embrittlement of titanium.

In order to increase the sensitivity to detect the presence of nitrogen in the oxide scale and the metal underneath, other IBA experiments were made with an ion beam energy of $1.9 \mathrm{MeV}$. The analysed area includes the whole thickness of the oxide layer and about $250 \mu \mathrm{m}$ of the metal below for the US- 


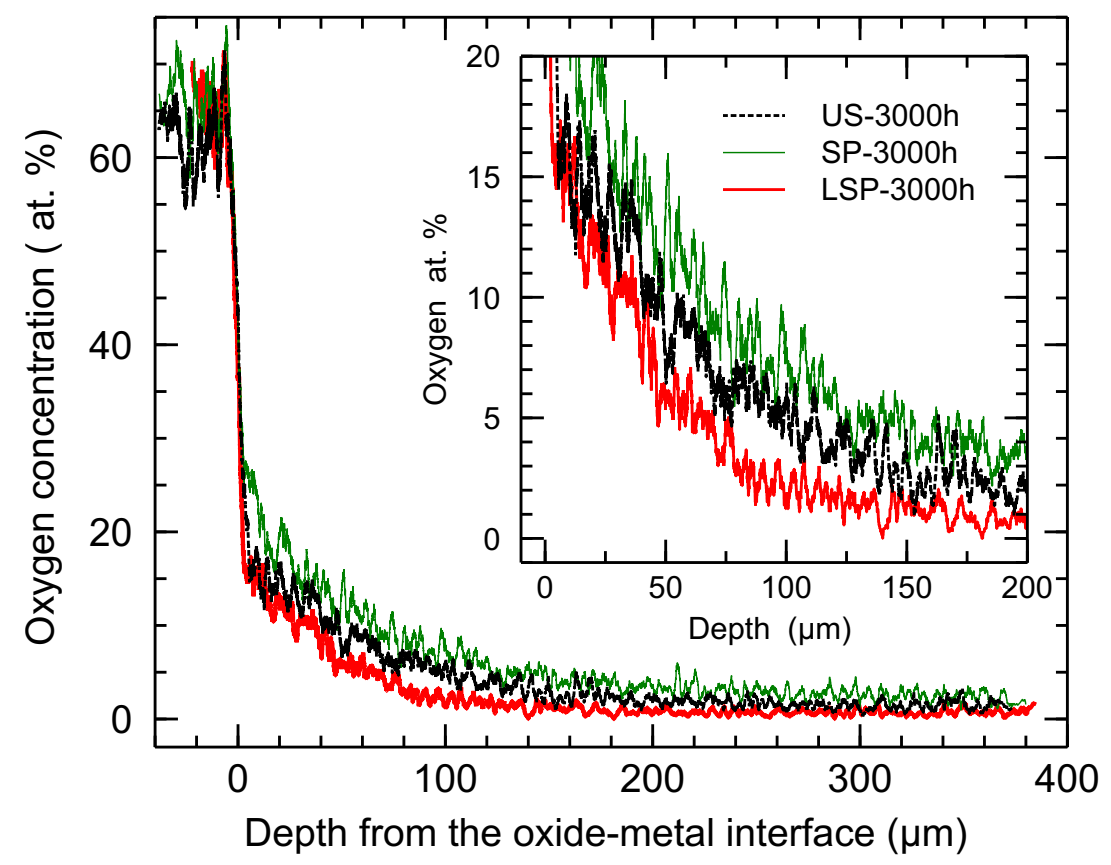

Figure 13: In-depth variation of the oxygen concentration below the interface between the surface oxidation layer and the metal for the samples US-3000h, SP-3000h and LSP-3000h. The oxygen concentration was determined by NRA analysis of the cross-section of the oxidized samples. 


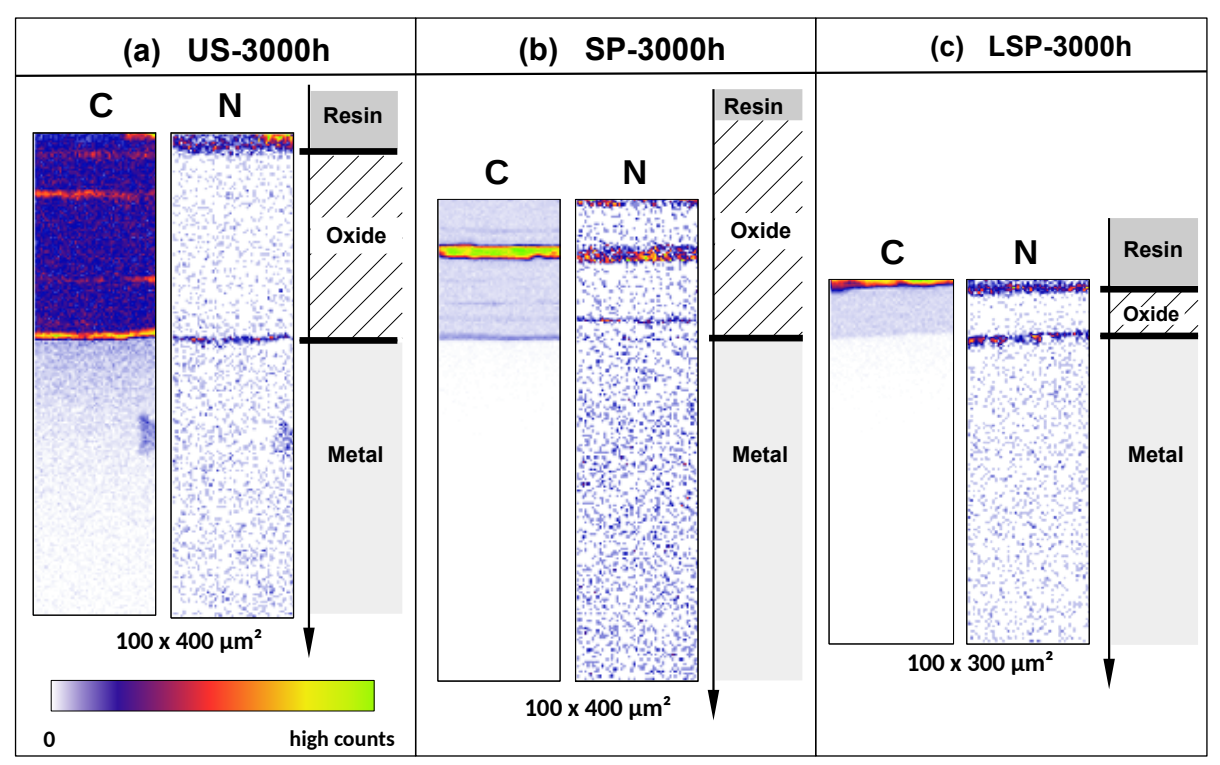

Figure 14: NRA maps displaying the spatial distribution of the isotopes ${ }^{12} C$ and ${ }^{14} N$ in the cross-section of the samples US-3000h, SP-3000h and LSP-3000h. A sketch shows roughly the structure of the samples along the cross-section. For SP-3000h, only the inner part of the oxide layer has been analysed. Experimental conditions: deuteron beam at $1.90 \mathrm{MeV}$, detection angle of $170^{\circ}, 50 \mu \mathrm{m}$ thick annular Mylar foil. Carbon map: intensity of the $C 1$ nuclear reaction. Nitrogen map: integrated intensity of the $N 1, N 2, N 5$ and $N 6$ reactions.

3000h and LSP-3000h samples, while only the inner part of the oxide layer and about $300 \mu \mathrm{m}$ below were analysed for the SP-3000h sample. The NRA spectra obtained within this experimental conditions for US-3000h, SP-3000h and LSP3000h samples are given in Figure S5b. The relative intensity of the nuclear reactions of nitrogen were higher in these case compared to the $O 1$ and $O 2$ reaction of the ${ }^{16} \mathrm{O}$ isotope and the $C 1$ reaction of ${ }^{12} C$. In the $3-10 \mathrm{MeV}$ range, only reactions assigned to nitrogen were detected. So, the integrated intensity in this range was used to map the spatial distribution of nitrogen. The $C 1$ nuclear reaction of carbon was used again to map the distribution of carbon.

Figure 14 shows the spatial distribution of ${ }^{14} N$ and ${ }^{12} C$ isotopes in the cross section of three samples (US-3000h, SP-3000h and LSP-3000h). A schematic representation shows the structure of the samples along the cross-section. The 
resin used for coating the samples contains carbon and nitrogen. So, both elements are detected together on top of the oxide layer for samples US-3000h and LSP-3000h. They are also detected together in the metal/oxide interface of the US-3000h sample which can be due to pollution during the polishing process. For the SP-3000h sample, the signals of carbon and nitrogen at the metal/oxide interface are low in the analyzed area, but they are high in a wide strip in the oxide scale, which can be explain by pollution in a crack. Figures and $10 \mathrm{~b}$ and $11 \mathrm{~b}$ show multiple cracks in the oxide layer which can even fill with resin during the coating of the samples before their transverse cutting.

More interesting is the detection of nitrogen alone, without carbon mainly at the oxide/metal interface for the LSP-3000h sample. It shows that an interfacial nitrogen-rich layer is still protecting the metal against oxygen diffusion after $3000 \mathrm{~h}$ of exposure to high temperature. Indeed, as oxygen and nitrogen occupy the same insertion sites in the titanium structure [43], the insertion of nitrogen prevents that of oxygen. This result allows to explain the thin layer of darker grains observed by SEM at the top of the metal substrate for the LSP-3000h sample by the insertion of nitrogen. This nitrogen-rich layer can promote the accommodation of the oxide scale on the metal by reducing stress at the interface [44] which would improve the adherence of the scale onto the metal. Both effects promote the preservation of a thick dense protective oxide scale, which slows down the oxygen flux within the core of the material and explain the higher oxidation resistance of LSP treated titanium compared to untreated or SP treated titanium.

\section{Conclusions}

The role of atmospheric nitrogen in the high temperature oxidation in air of ultrasonically shot-peened (SP) and laser-shock peened (LSP) pure titanium has been investigated and compared with untreated titanium. Ion beam analysis and nuclear microprobe methods were used to study the insertion and spatial distribution of atmospheric nitrogen and oxygen in samples oxidized at $700{ }^{\circ} \mathrm{C}$ 
in dry air for short (5-10 h) and long exposure times (3000 h).

The analysis of mechanically treated titanium before oxidation experiments has shown that the SP treatment gives rise to a huge density of twins under the sample surface up to about $70 \mu \mathrm{m}$ in depth. The LSP treatment induces the formation of a lower number of twins which are spread several hundred of microns below the surface.

For short exposure to high temperature, it was found that the SP treatment improves the oxidation resistance of pure titanium. Under the same conditions, the LSP treatment does not reduce the oxidation mass gain. The insertion of nitrogen was detected by IBA in 5h-oxidized samples for both untreated and mechanically treated titanium. The experimental IBA spectra were modeled using the SIMNRA software on the basis of a multilayered structure of the scale and the diffusion of oxygen and/or nitrogen in the metal. It was concluded that, independently of the mechanical treatment, an interfacial layer of $\mathrm{Ti}_{2} \mathrm{~N}$ is formed under the oxide. In the metal below, we found the diffusion of nitrogen in LSP treated titanium instead of oxygen as found for untreated ans SP treated titanium. Cross-section SEM-BSE observations supported the insertion of nitrogen at the oxide/metal interface, and XRD analysis showed the formation of nitride and/or oxynitride titanium.

For long exposure times (3000 h), only LSP increases the oxidation resistance of titanium. In this case, the oxide scale is dense and adheres well to the metal. In the absence of cracks and spallation, the oxide scale protects the metal against a larger oxygen flow. For the SP treatment, despite the reduction of the shortterm oxidation, the efficiency of the treatment is lost for long-term oxidation due to the spallation of the oxide scale.

The analyses of the cross-section distribution of oxygen and nitrogen in 3000h-oxidized samples showed the formation of a nitrogen-rich layer between the oxide layer and the metal below detected only for laser-shock treated titanium. This result was supported by cross-section SEM-BSE images which showed a thin layer of darker grains at the top of the metal substrate. The protective role of this layer in slowing down the diffusion of oxygen into the 
metal was confirmed by the in-depth micro-hardness profile along the crosssection. The profile obtained by IBA analysis of the concentration of oxygen in the metal under the oxide layer allows to conclude that the core of LPS treated samples is nearly oxygen-free in long-term oxidized titanium, which is not the case for untreated and SP treated titanium. As a result, only the LSP treatments prevents the embrittlement of titanium due to the diffusion of oxygen $(\alpha$-case).

In summary, atmospheric nitrogen plays a key role to explain the effect of surface mechanical treatments on the high temperature oxidation resistance of pure titanium, and in particular the efficient protection provided by laser-shock peening treatments against long-term oxidation.

\section{Acknowledgements}

The authors thank O. Heintz, N. Geoffroy and F. Herbst from the ICB laboratory and M. Saint-Jean from the IUT Chalon sur Saône for their contribution to the experimental observations and analyses. This work has been supported by the EIPHI Graduate School (contract ANR-17-EURE-0002).

\section{Data availability}

The raw/processed data required to reproduce these findings cannot be shared at this time as the data also forms part of an ongoing study.

\section{References}

[1] I. Inagaki, Y. Shirai, T. Takechi, N. Ariyasu, Application and features of titanium for the aerospace industry, Nippon Steel \& Sumitomo Metal Technical Report 106 (2014) 22-27.

[2] Z. Huda, P. Edi, Materials selection in design of structures and engines of supersonic aircrafts: A review, Materials \& Design 46 (2013) 552-560. 
[3] C. Leyens, M. Peters (Eds.), Titanium and Titanium Alloys: Fundamentals and Applications, John Wiley \& Sons, Ltd, 2003.

[4] M. Peters, J. Kumpfert, C. Ward, C. Leyens, Titanium alloys for aerospace applications, Advanced Engineering Materials 5 (2003) 419-427.

[5] E. Maawad, Y. Sano, L. Wagner, H.-G. Brokmeier, C. Genzel, Investigation of laser shock peening effects on residual stress state and fatigue performance of titanium alloys, Materials Science and Engineering: A 536 (2012) 82-91.

[6] W. Jia, Q. Hong, H. Zhao, L. Li, D. Han, Effect of laser shock peening on the mechanical properties of a near- $\alpha$ titanium alloy, Materials Science and Engineering: A 606 (2014) 354-359.

[7] X. Zhang, Y. Zhang, J. Lu, F. Xuan, Z. Wang, S. Tu, Improvement of fatigue life of $\mathrm{Ti}-6 \mathrm{Al}-4 \mathrm{~V}$ alloy by laser shock peening, Materials Science and Engineering: A 527 (2010) 3411-3415.

[8] X. Jiang, X. Wang, J. Li, D. Li, C.-S. Man, M. Shepard, T. Zhai, Enhancement of fatigue and corrosion properties of pure Ti by sandblasting, Materials Science and Engineering: A 429 (2006) 30-35.

[9] X. Jiang, C.-S. Man, M. Shepard, T. Zhai, Effects of shot-peening and reshot-peening on four-point bend fatigue behavior of $\mathrm{Ti}-6 \mathrm{Al}-4 \mathrm{~V}$, Materials Science and Engineering: A 468-470 (2007) 137-143.

[10] L. Raceanu, V. Optasanu, T. Montesin, G. Montay, M. François, Shotpeening of pre-oxidized plates of zirconium: Influence of residual stress on oxidation, Oxidation of Metals 79 (2012) 135-145.

[11] M. Wen, C. Wen, P. Hodgson, Y. Li, Thermal oxidation behaviour of bulk titanium with nanocrystalline surface layer, Corrosion Science 59 (2012) 352-359. 
[12] M. Wen, C. Wen, P. Hodgson, Y. Li, Improvement of the biomedical properties of titanium using SMAT and thermal oxidation, Colloids and Surfaces B: Biointerfaces 116 (2014) 658-665.

[13] K. Zhu, A. Vassel, F. Brisset, K. Lu, J. Lu, Nanostructure formation mechanism of $\alpha$-titanium using SMAT, Acta Materialia 52 (2004) 41014110.

[14] S. Bagheri, M. Guagliano, Review of shot peening processes to obtain nanocrystalline surfaces in metal alloys, Surface Engineering 25 (2009) $3-14$.

[15] Y. Hua, Y. Bai, Y. Ye, Q. Xue, H. Liu, R. Chen, K. Chen, Hot corrosion behavior of TC11 titanium alloy treated by laser shock processing, Applied Surface Science 283 (2013) 775-780.

[16] A. Kanjer, L. Lavisse, V. Optasanu, P. Berger, C. Gorny, P. Peyre, F. Herbst, O. Heintz, N. Geoffroy, T. Montesin, M. C. Marco de Lucas, Effect of laser shock peening on the high temperature oxidation resistance of titanium, Surface and Coatings Technology 326 (2017) 146-155.

[17] A. Kanjer, V. Optasanu, L. Lavisse, M. C. Marco de Lucas, S. Dejardin, M. François, P. Berger, P. Peyre, C. Gorny, T. Montesin, Influence of mechanical surface treatment on high-temperature oxidation of pure titanium, Oxidation of Metals 88 (2017) 383-395.

[18] D. He, L. Li, W. Guo, G. He, P. Peng, T. Shao, H. Huan, G. Zhang, G. Han, J. Yan, Improvement in oxidation resistance of $\mathrm{Ti}_{2} \mathrm{AlNb}$ alloys at high temperatures by laser shock peening, Corrosion Science 184 (2021) 109364 .

[19] A. Chaze, C. Coddet, The role of nitrogen in the oxidation behaviour of titanium and some binary alloys, Journal of the Less Common Metals 124 (1986) 73-84. 
[20] J. Unnam, R. N. Shenoy, R. K. Clark, Oxidation of commercial purity titanium, Oxidation of Metals 26 (1986) 231-252.

[21] C. Coddet, A. M. Craze, G. Beranger, Measurements of the adhesion of thermal oxide films: application to the oxidation of titanium, Journal of Materials Science 22 (1987) 2969-2974.

[22] P. Lefort, J. Desmaison, M. Billy, Sur le mécanisme de l'oxydation linéaire du titane dans l'oxygène, Comptes rendus de l'Académie des Sciences (France), Série C 286 (1978) 361-364.

[23] C. Dupressoire, A. Rouaix-Vande Put, P. Emile, C. Archambeau-Mirguet, R. Peraldi, D. Monceau, Effect of nitrogen on the kinetics of oxide scale growth and of oxygen dissolution in the Ti6242S titanium-based alloy, Oxidation of Metals 87 (2017) 343-353.

[24] IAEA-International Atomic Energy Agency, Ion beam techniques for the analysis of light elements in thinfilms, including depth profiling IAEATECDOC-1409 (2004).

[25] M. Berthaud, I. Popa, R. Chassagnon, O. Heintz, J. Lavková, S. Chevalier, Study of titanium alloy Ti6242S oxidation behaviour in air at $560{ }^{\circ} \mathrm{C}$ : Effect of oxygen dissolution on lattice parameter, Corrosion Science 164 (2020) 108049 .

[26] I. Abdallah, C. Dupressoire, L. Laffont, D. Monceau, A. Vande Put, STEMEELS identification of $\mathrm{TiO}_{x} \mathrm{~N}_{y}, \mathrm{TiN}, \mathrm{Ti}_{2} \mathrm{~N}$ and $\mathrm{O}, \mathrm{N}$ dissolution in the Ti2642S alloy oxidized in synthetic air at $650{ }^{\circ} \mathrm{C}$, Corrosion Science 153 (2019) 191-199.

[27] C. Dupressoire, M. Descoins, A. V. Put, E. Epifano, D. Mangelinck, P. Emile, D. Monceau, The role of nitrogen in the oxidation behaviour of a Ti6242S alloy: a nanoscale investigation by atom probe tomography, Acta Materialia 216 (2021) 117134. 
[28] J.-Y. Xu, Z.-Z. Shi, Z.-B. Zhang, H.-G. Huang, X.-F. Liu, Significant enhancement of high temperature oxidation resistance of pure titanium via minor addition of Nb and Si, Corrosion Science 166 (2020) 108430.

[29] T.Kitashima, T. Hara, Y. Yang, Y. Hara, Oxidation-nitridation-induced recrystallization in a near- $\alpha$ titanium alloy, Materials and Design 137 (2018) 355-360.

[30] A. Kanjer, V. Optasanu, M. C. Marco de Lucas, O. Heintz, N. Geoffroy, M. François, P. Berger, T. Montesin, L. Lavisse, Improving the high temperature oxidation resistance of pure titanium by shot-peening treatments, Surface and Coatings Technology 343 (2018) 93-100.

[31] H. Khodja, E. Berthoumieux, L. Daudin, J.-P. Gallien, The Pierre Süe Laboratory nuclear microprobe as a multi-disciplinary analysis tool, Nuclear Instruments and Methods in Physics Research Section B: Beam Interactions with Materials and Atoms 181 (2001) 83-86.

[32] L. Lavisse, P. Berger, M. Cirisan, J. M. Jouvard, S. Bourgeois, M. C. Marco de Lucas, Influence of laser-target interaction regime on composition and properties of surface layers grown by laser treatment of Ti plates, Journal of Physics D: Applied Physics 42 (2009) 245303.

[33] International Atomic Energy Agency, Ion beam analysis nuclear data library (IBANDL), http://www-nds.iaea.org/ibandl, 2019.

[34] D. D. Cohen, E. K. Rose, Analysis of oxygen by charged particle bombardment, Nuclear Instruments and Methods in Physics Research Section B: Beam Interactions with Materials and Atoms 66 (1992) 158-190.

[35] A. Gurbich, S. Molodtsov, Measurement of $(\mathrm{d}, \mathrm{p})$ and $(\mathrm{d}, \alpha)$ differential cross-sections for ${ }^{14} \mathrm{~N}$, Nuclear Instruments and Methods in Physics Research Section B: Beam Interactions with Materials and Atoms 266 (2008) $1206-1208$. 
[36] C. Cellard, D. Retraint, M. François, E. Rouhaud, D. L. Saunier, Laser shock peening of Ti-17 titanium alloy: Influence of process parameters, Materials Science and Engineering: A 532 (2012) 362-372.

[37] D. Monceau, B. Pieraggi, Determination of parabolic rate constants from a local analysis of mass-gain curves, Oxidation of metals 50 (1998) 477-493.

[38] J. H. Hubbell, S. M. Seltzer, Tables of X-ray mass attenuation coefficients and mass energy-absorption coefficients, NIST Standard Reference Database 126, Last update: July 2004 (2004).

[39] J. Nazon, P. Simon, B. Domenichini, S. Bourgeois, Thermal stability under air of tungsten-titanium diffusion barrier layer between silica and platinum, Corrosion Science 78 (2014) 208-214.

[40] P. Kofstad, High-temperature oxidation of titanium, Journal of the Less Common Metals 12 (1967) 449-464.

[41] J. Baillieux, D. Poquillon, B. Malard, Observation using synchrotron xray diffraction of the crystallographic evolution of $\alpha$-titanium after oxygen diffusion, Philosophical Magazine Letters 95 (2015) 245-252.

[42] P. Trocellier, P. Berger, M. Wilde, Nuclear Reaction Analysis, American Cancer Society, 2016, pp. 1-17.

[43] T. Tsuji, Thermochemistry of IVA transition metal-oxygen solid solutions, Journal of Nuclear Materials 247 (1997) 63-71.

[44] F. Torrent, L. Lavisse, P. Berger, G. Pillon, C. Lopes, F. Vaz, M. C. Marco de Lucas, Influence of the composition of titanium oxynitride layers on the fretting behavior of functionalized titanium substrates: PVD films versus surface laser treatments, Surface and Coatings Technology 255 (2014) 146152. 